\title{
Snail Coordinately Regulates Downstream Pathways to Control Multiple Aspects of Mammalian Neural Precursor Development
}

\author{
Mark A. Zander, ${ }^{1,2}$ Sarah E. Burns, ${ }^{1}$ Guang Yang, ${ }^{1}$ David R. Kaplan, ${ }^{1,2,3}$ and Freda D. Miller ${ }^{1,2,3,4}$ \\ ${ }^{1}$ Neuroscience and Mental Health Program, Hospital for Sick Children, Toronto, Ontario M5G 1L7, Canada, and ${ }^{2}$ Institute of Medical Science and \\ Departments of ${ }^{3}$ Molecular Genetics and ${ }^{4}$ Physiology, University of Toronto, Toronto, Ontario M5G 1X5, Canada
}

\begin{abstract}
The Snail transcription factor plays a key role in regulating diverse developmental processes but is not thought to play a role in mammalian neural precursors. Here, we have examined radial glial precursor cells of the embryonic murine cortex and demonstrate that Snail regulates their survival, self-renewal, and differentiation into intermediate progenitors and neurons via two distinct and separable target pathways. First, Snail promotes cell survival by antagonizing a p53-dependent death pathway because coincident $\mathrm{p} 53 \mathrm{knockdown}$ rescues survival deficits caused by Snail knockdown. Second, we show that the cell cycle phosphatase Cdc25b is regulated by Snail in radial precursors and that $\mathrm{Cdc} 25 \mathrm{~b}$ coexpression is sufficient to rescue the decreased radial precursor proliferation and differentiation observed upon Snail knockdown. Thus, Snail acts via p53 and Cdc25b to coordinately regulate multiple aspects of mammalian embryonic neural precursor biology.
\end{abstract}

Key words: cdc25; cortical development; neural stem cell; p53; radial glial precursor; self-renewal

\section{Introduction}

The mechanisms that regulate mammalian stem cell biology are still not well understood. In this regard, the Snail transcription factor family, which activates and represses transcription (De Craene et al., 2005), regulates multiple aspects of stem cell behavior in organisms ranging from invertebrates to humans. In vertebrates, Snail and the related family member Snail2 (Slug) are perhaps best known for regulating the epithelial-mesenchymal transition. For example, the Snail family regulates neural crest precursors when they delaminate from the neural tube (Acloque et al., 2009). However, in lower organisms, Snail family members play broader roles in regulating stem cell biology. In Caenorhabditis elegans, the Snail ortholog CES-1 promotes survival of one daughter cell during asymmetric precursor divisions by suppressing a $\mathrm{BH} 3$ protein-dependent apoptotic pathway (Thellmann et al., 2003; Hatzold and Conradt, 2008). In Drosophila, three family members (Snail, Escargot, and Worniu) act together to regulate both asymmetry and cell division in neuroblasts, at least in part

Received Jan. 27, 2014; revised Feb. 26, 2014; accepted March 1, 2014.

Author contributions: M.A.Z., D.R.K., and F.D.M. designed research; M.A.Z., S.E.B., and G.Y. performed research; M.A.Z. and F.D.M. analyzed data; M.A.Z., D.R.K., and F.D.M. wrote the paper.

This work was supported by Canadian Institutes of Health Research Grants MOP-38021 and MOP-13958 to F.D.M. and D.R.K., F.D.M. is an HHMI Senior International Research Scholar. F.D.M. and D.R.K. hold CRC Chairs. M.A.Z. was supported by an Ontario Graduate Scholarship. G.Y. was supported by a Brain Canada Mental Health fellowship. We thank Barbara Conradt for the initial suggestion that Snail might regulate asymmetric cell death in the embryonic cortex, Andras Nagy for the kind gift of plasmids, Dennis Benigno Aquino for maintaining mouse colonies, and Vania Ariosa for genotyping mouse colonies.

The authors declare no competing financial interests.

Correspondence should be addressed to Dr. Freda D. Miller, Neuroscience and Mental Health Program, Hospital for Sick Children, 18-9716, 686 Bay Street, Toronto, Ontario M5G 0A4. Canada. E-mail: fredam@sickkids.ca.

DOI:10.1523/JNEUROSCI.0370-14.2014

Copyright $\odot 2014$ the authors $\quad 0270-6474 / 14 / 345164-12 \$ 15.00 / 0$ by regulating expression of inscuteable and string (Ashraf and Ip 2001; Cai et al., 2001). Intriguingly, mouse Inscuteable plays a key role in murine neural precursor asymmetric cell division (Postiglione et al., 2011), and the vertebrate string homolog, the cell cycle phosphatase Cdc25b, is important in the embryonic chick spinal cord (Peco et al., 2012). However, despite these parallels, Snail is not thought to play a role in mammalian neural stem cells.

To address a potential role for Snail in mammalian neural precursors, we focused on the radial glial precursor cells that build the embryonic murine cortex. During development, these precursors divide symmetrically to self-renew, and asymmetrically to generate either neurons or the neurogenic transitamplifying cells in this system, intermediate progenitors. Later in development, radial precursors also generate glial cells, and some persist to become adult forebrain neural stem cells. Intriguingly, a number of recent reports suggest that the cellular mechanisms controlling the behavior of these developing radial precursors are, in part, conserved between Drosophila and mammals (Schwamborn et al., 2009; Postiglione et al., 2011; Kusek et al., 2012; Vessey et al., 2012), raising the possibility that Snail might be important in mammalian neural stem cells.

Here, we provide evidence that Snail determines multiple aspects of cortical radial precursor development, including their survival, proliferation, and differentiation. Moreover, we show that it does so via several downstream target pathways, regulating cell survival via a $\mathrm{p} 53$-dependent mechanism, and proliferation and differentiation via Cdc25b. Thus, Snail acts via conserved downstream target pathways to coordinately regulate multiple aspects of neural stem cell biology. 


\section{Materials and Methods}

Animals. All animal use was approved by the Animal Care Committee of the Hospital for Sick Children in accordance with the Canadian Council of Animal Care policies. CD1 mice, purchased from Charles River Laboratory, were used for all culture and electroporation experiments. Sox2: EGFP mice (Ellis et al., 2004) maintained on a C57BL/6 background were used for sorting experiments and were genotyped and maintained as described previously (Biernaskie et al., 2009). Mice and embryos of both sexes were used.

Primers and plasmids. Snail mRNA was detected using Snail forward (5' -GCCGGAAGCCCAACTATAGCGA3') and Snail reverse (5' -AGAG CGCCCAGGCTGAGGTACT- $3^{\prime}$ ) primers. The product was verified by sequence analysis. The nuclear EGFP expression plasmid was driven from the Ef1 $\alpha$ (Efla-Mouse Genome Informatics) promoter (pEF-EGFP) and has been previously described (Barnabé-Heider et al., 2005). The PB-EGFP contains an EGFP reporter driven by the CAG promoter and flanked by inverted repeats (ITRs) that are recognized by the PB transposase (Woltjen et al., 2009). The Snail shRNAs and the negative control shRNA were purchased from Open Biosystems and made in the pLKO.1 backbone. The targeted sequences are 5'-GCCACCTTCTTTGAGGTACAA-3' for Snail shRNA1 and 5' -GCGGAAGATCTTCAACTGCAA- 3 ' for Snail shRNA2. The sequence for the shRNA-negative control was $5^{\prime}$-AGTCACGACGTTGTAATACGA-3'. The mouse Snail expression vector was generated from IMAGE clone 5121591 by subcloning into pcDNA3.1(+) (Invitrogen). The human Snail expression vector was generated from IMAGE clone 4537122 by subcloning into pEFGM (Barnabé-Heider et al., 2005). The p53 shRNA was kindly provided by Dr. Reuven Agami's laboratory (Netherlands Cancer Institute) (Brummelkamp et al., 2002). Murine $\mathrm{Cdc} 25 \mathrm{~b}$ and Snail2 expression constructs were purchased from Origene.

Cortical precursor cell cultures. Cortical precursor cells were cultured as previously described (Barnabé-Heider et al., 2005). Briefly, cerebral cortices were dissected from E12 CD1 mouse embryos in ice-cold HBSS (Invitrogen) and placed into Neurobasal medium (Invitrogen) containing $500 \mu \mathrm{M} \mathrm{L}$-glutamine (Cambrex Biosciences), 2\% B27 supplement (Invitrogen), 1\% penicillin-streptomycin (Invitrogen), and $40 \mathrm{ng} / \mathrm{ml}$ FGF2 (BD Biosciences). This tissue was mechanically triturated upon multiple passes through a $\mathrm{P} 1000$ pipette tip and plated at a density of $200,000 \mathrm{cell} / \mathrm{ml}$ in 4 well chamber slides (Nunc) precoated with $2 \%$ laminin (BD Biosciences) and 1\% poly-D-lysine (Sigma). Culture medium was not changed for the duration of the experiment. For transfections, $1 \mu \mathrm{g}$ of total DNA was diluted in $100 \mu$ l of Opti-MEM (Invitrogen) and $2 \mu \mathrm{l}$ of Fugene 6.0 (Promega), incubated at room temperature for $1 \mathrm{~h}$ and added to cultures $1 \mathrm{~h}$ after plating. This resulted in a transfection of, at most, $1-3 \%$ of cells. For knockdown experiments, we used a 1:2 ratio of EGFP to shRNA plasmids $(0.33 \mu \mathrm{g}$ of pEGFP plasmid plus $0.66 \mu \mathrm{g}$ of Snail shRNA1, Snail shRNA2, or negative control shRNA plasmid). For the rescue experiments, we used a 1:6:3 ratio of EGFP to overexpression construct to knockdown plasmid for a total of $1 \mu \mathrm{g}$ of DNA $(0.1 \mu \mathrm{g}$ of pEGFP plus $0.6 \mu \mathrm{g}$ of pEFGM or H.Snail and $0.3 \mu \mathrm{g}$ of Snail shRNA1, Snail shRNA2, or negative control shRNA). For Snail overexpression experiments, we used a ratio of 1:1:3 of plasmids encoding PB transposase, $\mathrm{PB}$ reporter, and overexpression construct for a total of $1.25 \mu \mathrm{g}$ of DNA $(0.25 \mu \mathrm{g}$ of PB transposase plasmid plus $0.25 \mu \mathrm{g}$ of PB-EGFP plasmid, and $0.75 \mu \mathrm{g}$ of pEFGM or H.Snail plasmid).

In utero electroporation. In utero electroporation was performed as described previously (Gauthier et al., 2007) with E13/E14 CD1 mice, injecting a 1:3 ratio of the nuclear EGFP plasmid with the shRNA or overexpression plasmids (total of $4 \mu \mathrm{g}$ of DNA) and $0.5 \%$ trypan blue as a color indicator for successful injection of plasmid DNA. For the rescue experiments, DNA was mixed at a ratio of $0.75 \mu \mathrm{g}$ of pEF-EGFP plus 2.25 $\mu \mathrm{g}$ of p53 shRNA plus $2.25 \mu \mathrm{g}$ of Snail shRNA for a total of $5.25 \mu \mathrm{g}$ of DNA per embryo. For the Cdc25b rescue experiments, DNA was mixed at a ratio of $0.75 \mu \mathrm{g}$ of pEF-EGFP plus $2.25 \mu \mathrm{g}$ of Cdc25b expression plasmid plus $2.25 \mu \mathrm{g}$ of Snail shRNA for a total of $5.25 \mu \mathrm{g}$ of DNA per embryo. The square electroporator CUY21 EDIT (TR Tech) was used to deliver five $50 \mathrm{~ms}$ pulses of $40-50 \mathrm{~V}$ with $950 \mathrm{~ms}$ intervals per embryo. Brains were dissected $3 \mathrm{~d}$ after transfection in ice-cold HBSS, fixed in $4 \%$ paraformaldehyde at $4^{\circ} \mathrm{C}$ overnight, cryopreserved, and cryosectioned coronally at $16 \mu \mathrm{m}$.

Immunocytochemistry and histological analysis. Immunocytochemistry on cultured cells and cryosections was performed as previously described (Barnabé-Heider et al., 2005), except for immunostaining for Snail. The primary antibodies used were rabbit anti-GFP (1:5000; Abcam), chicken anti-GFP (1:1000; Abcam), mouse anti- $\beta$ III-tubulin (1:1000; Covance), rabbit anti-Pax6 (1:1000; Covance), rabbit anti-Tbr2 (1:250; Abcam), mouse anti-Satb2 (1:400; Abcam), rabbit anti-cleaved caspase 3 (1:200; Millipore), mouse anti-Ki67 (1:200; BD Biosciences), goat anti-Snail53519 (1:1000 for paraffin sections and 1:2000 for cultured cells; Abcam), rat anti-Nestin (1:200; BD Biosciences), rabbit anti-pH3 (1:250; Millipore), rabbit-Cdc25B (1:200; Cell Signaling Technology), and rabbit anti-BrdU (1:200; Accurate Chemical). The secondary antibodies used were AlexaFluor-555-, AlexaFluor-488-, and AlexaFluor-647-conjugated goat/rat antibodies to mouse, rabbit, goat, and chicken IgG (1: 1000 for 488/555, 1:500 for 647; Invitrogen). For Cdc25b immunostaining, sections were dried for $20 \mathrm{~min}$ and then incubated in antigen retrieval buffer (target retrieval buffer, $\mathrm{pH}$ 9; Dako) for $30 \mathrm{~min}$ at $95^{\circ} \mathrm{C}$ and then washed in $1 \times$ PBS for 5 min before blocking as usual. For Snail immunostaining, embryonic brains were formalin-fixed and paraffinembedded; and after cutting, sections were deparaffinized with xylene and rehydrated with an ethanol gradient. Antigen retrieval was performed with $10 \mathrm{~mm}$ sodium citrate buffer, $\mathrm{pH}$ 6, with $0.05 \%$ Tween 20 at $95^{\circ} \mathrm{C}$ for $20 \mathrm{~min}$. Sections were blocked at room temperature with $4 \%$ donkey serum in PBS and incubated with goat anti-Snail 53519 (1:1000; Abcam) overnight at $4^{\circ} \mathrm{C}$. Sections were washed with PBS containing $0.2 \%$ Tween 20 and detected using donkey anti-goat AlexaFluor-555 at 1:1000 in PBS. Nuclei were stained with Hoechst 33258 (Sigma). BrdU staining was performed on embryonic brains that were fixed in $4 \%$ PFA overnight followed by cryopreservation in $30 \%$ sucrose overnight.

$B r d U$ experiments. For embryonic analyses pregnant CD1 mice were injected with BrdU (Sigma) dissolved in PBS at a dose of $100 \mathrm{mg}$ per $\mathrm{kg}$ of body weight $2 \mathrm{~d}$ after electroporation. For immunostaining of sections from these mice, sections were dried for $20 \mathrm{~min}$, incubated in $0.5 \mathrm{~N} \mathrm{HCl}$ for $30 \mathrm{~min}$ at $60^{\circ} \mathrm{C}$, and washed in $1 \times$ PBS buffer for $5 \mathrm{~min}$ before blocking as usual.

Western blot analysis. Western blots were performed as described previously (Barnabé-Heider et al., 2005). Cortical tissue or cells were harvested in radioimmunoprecipitation assay lysis buffer supplemented with $1 \mathrm{~mm}$ PMSF, $1 \mathrm{~mm} \mathrm{Na} \mathrm{VO}_{4}, 10 \mu \mathrm{g} / \mathrm{ml}$ aprotenin, and $10 \mu \mathrm{g} / \mathrm{ml}$ leupeptin and then incubated for $30 \mathrm{~min}$ at $4^{\circ} \mathrm{C}$. Protein concentration was determined using the BCA Protein Assay Kit (Thermo Fisher Scientific). Protein lysates of $50 \mu \mathrm{g}$ were loaded onto each lane of a $10 \%$ SDS gel. Proteins were transferred to nitrocellulose membranes (Bio-Rad) at $110 \mathrm{~V}$ for $90 \mathrm{~min}$ at $4^{\circ} \mathrm{C}$. Membranes were then blocked with 5\% BSA in Tris-buffered saline-Tween 20 (TBST) for $60 \mathrm{~min}$, incubated with primary antibodies diluted in TBST alone at $4^{\circ} \mathrm{C}$ overnight, and probed with secondary antibodies diluted in TBST and incubated for $30 \mathrm{~min}$ at room temperature. Three $5 \mathrm{~min}$ washes were applied after each step. Blots were developed after incubating membranes in enhanced chemiluminescence (GE Healthcare) for $5 \mathrm{~min}$ and then exposed for different time periods. The antibodies used were goat anti-Snail E18 (1:1000; Santa Cruz Biotechnology) or goat anti-Snail-53519 (1:1000; Abcam), and HRPconjugated donkey anti-goat (1:10,000; Santa Cruz Biotechnology).

Flow cytometry. E13 littermate embryos were harvested from crosses between Sox2:EGFP and wild-type C57BL/6 mice. EGFP-positive and -negative animals were separated, and cortical cells were harvested as described for the culture experiments, dissociated to single cells in $1 \%$ BSA, and sorted for EGFP expression on a MoFlo fluorescent activated cell sorter (Dako) with viable cells identified by propidium iodide exclusion as previously described (Biernaskie et al., 2009). Gates were set using cells isolated from the EGFP-negative cortices.

HEK 293 cell experiments. HEK 293 cells were cotransfected with mouse Snail1 or Snail2 expression vectors plus Snail or control shRNAs. In short, cells plated in $2 \mathrm{ml}$ of DMEM (Lonza) supplemented with 10\% FBS, $2 \mu \mathrm{M}$ L-glutamine (Cambrex Biosciences), and $1 \%$ penicillinstreptomycin (Invitrogen) in 6 well polystyrene multiwell plates (BD Falcon), and grown to confluency. The DNA was mixed together with 
$500 \mu \mathrm{l}$ of Opti-MEM (Invitrogen) and $5 \mu \mathrm{l}$ of Lipofectamine 2000 (Invitrogen) and incubated at room temperature for $20 \mathrm{~min}$. This medium was added dropwise to cells, and then cells were harvested $48 \mathrm{~h}$ later for analysis.

RT-PCR. Dissected mouse embryonic cortices were either directly subjected to RNA isolation, or plated and cultured as described above for the indicated number of days before RNA isolation. RNA was isolated using Trizol (Invitrogen) according to the manufacturer's protocol and was treated with DNase (Fermentas) to remove any contaminating genomic DNA. Reverse transcription was performed using RevertAid H Minus M-MuLV Reverse Transcriptase (Fermentas) primed with random hexamers, according to the manufacturer's instructions. All reactions were subjected to the following PCR protocol: $94^{\circ} \mathrm{C}$ for $2 \mathrm{~min}, 40$ cycles of $94^{\circ} \mathrm{C}$ for $15 \mathrm{~s}, 60^{\circ} \mathrm{C}$ for $30 \mathrm{~s}$ and $72^{\circ} \mathrm{C}$ for $30 \mathrm{~s}$, and a final elongation at $72^{\circ} \mathrm{C}$ for 2 min. Products were then resolved on a $2 \%$ agarose gel.

Microscopy and quantification. For quantification of cell culture experiments, a Zeiss Axioplan2 upright microscope equipped with fluorescence optics was used, and $>100$ cells per condition per experiment were counted and analyzed. For clonal experiments, $>50$ clones were analyzed per condition per experiment. A clone was defined as a cluster of EGFP-positive cells in close proximity to each other, which were clearly separated from other EGFP-positive clusters, and which were not separated by EGFP-negative cells. Digital image acquisition was performed with Axiocam software (Zeiss) using a Hamamatsu camera (Hamamatsu). For quantification of Cdc25b levels in cultured cortical precursors, cells were divided by eye into two groups: those with detectable or higher levels of nuclear Cdc25b staining (high/medium) and those where the staining in the nucleus was lower than the cytoplasm and/or was undetectable (low/no). For quantification of tissue sections, cortical sections were chosen that showed a similar anatomical distribution and number of EGFPpositive cells for comparison. Brains were sectioned at $16 \mu \mathrm{m}$ at E17/E18, and 3-4 brain sections at the same anatomical level per embryo were analyzed using an Olympus IX81 inverted fluorescence microscope equipped with a Hamamatsu C9100-13 back-thinned EM-CCD camera and Okogawa CSU X1 spinning disk confocal scan head. Stitching of $20 \times$ objective images was performed using Volocity (PerkinElmer) software to cover the electroporated ventricular zone (VZ), subventricular zone (SVZ), and cortical plate of each coronal section. Ventricular, subventricular, and cortical plate layers were delineated using Hoechst staining. For quantification of total cells per section, total EGFP-positive cells were counted in these stitched images to obtain total number of electroporated cells/section. For quantification of total electroporated cells that were positive for a given marker, the proportion of EGFP-positive cells expressing that marker was determined from quantification of a column
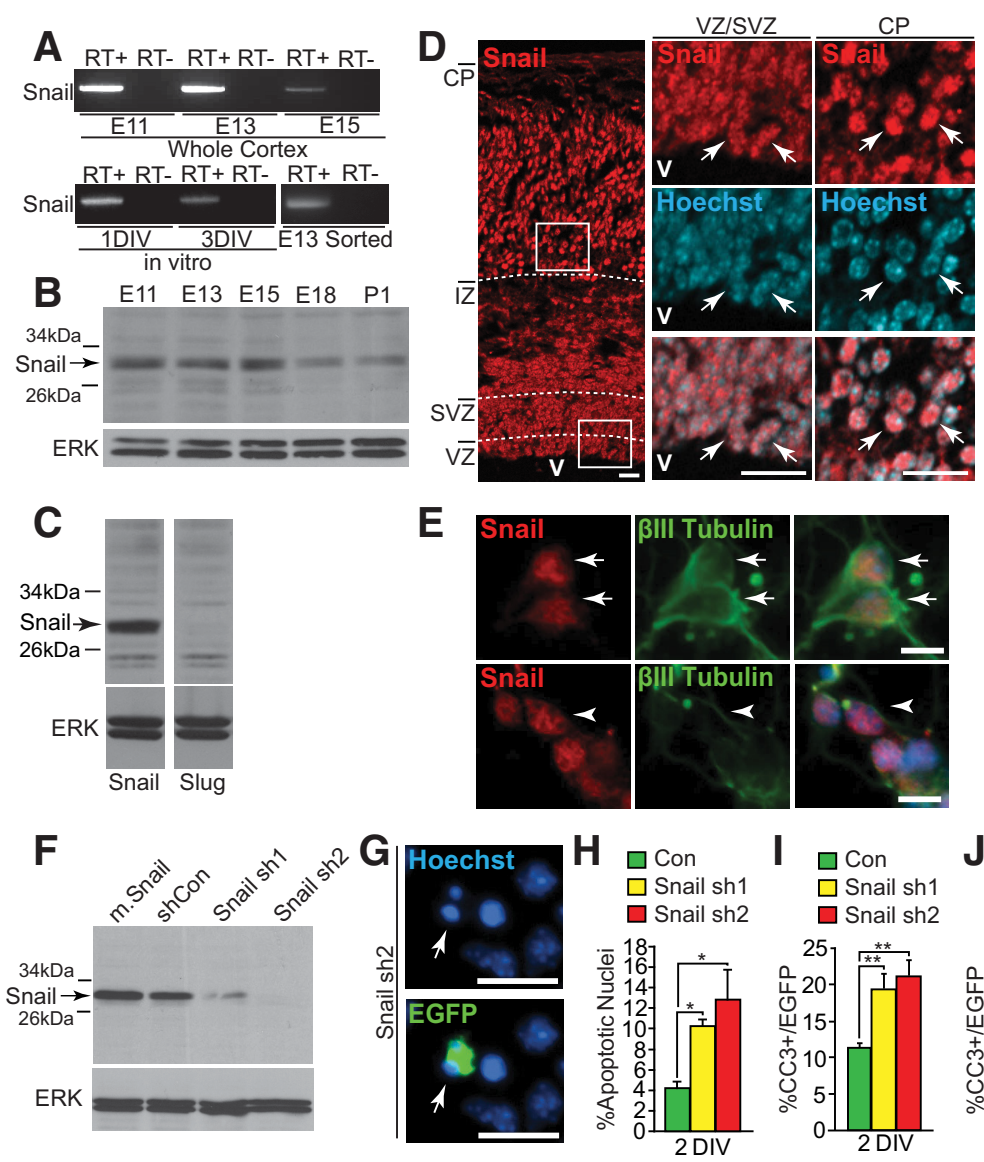

J acon

$\square$ Snail sh1 $\square$ Snail sh2

\section{K $\square$ Con}

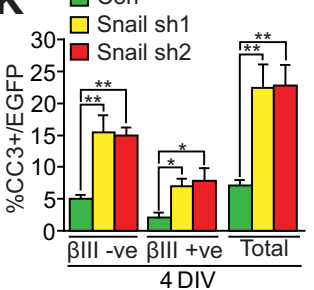

L

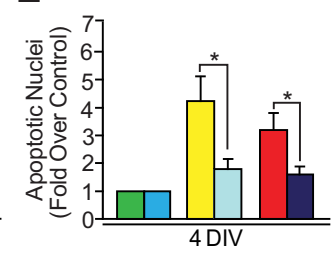

$\square$ Control + EV

$\square$ Snail sh1 + EV

$\square$ Snail sh2 + EV

$\square$ Control + H.Snail

$\square$ Snail sh1 + H.Snail

$\square$ Snail sh2 + H.Snail

Figure 1. Snail is expressed in embryonic cortical precursors and regulates their survival in culture. $A, R T-P C R$ analysis for Snail mRNA in the embryonic cortex at E11-E15 (top), in cortical precursors cultured for 1 or $3 \mathrm{~d}$ (bottom left, 1 DIV and 3 DIV), or in EGFP-positive precursors sorted from theE13Sox2:EGFP cortex (E13 sorted). The band was sequenced to confirm it was the correct product. RT - indicates samples where reverse transcriptase was omitted. $\boldsymbol{B}$, Western blot analysis for the $29 \mathrm{kDa}$ Snail protein in the cortex from E11 to P1. The blot was reprobed for total ERK protein as a loading control. $\boldsymbol{C}$, Western blot analysis of equal amounts of lysate from HEK 293 cells transfected with expression plasmids encoding Snail1 or Snail2 (Slug) probed with an antibody directed against Snail. The blot was reprobed for ERK to control for loading. D, Confocal micrographs of the E16.5 cortex immunostained for Snail (red). The boxed areas shown in the left panel are shown at higher magnification to the right, with the central panels showing the VZ/SVZ and the right panels showing the cortical plate. Sections were counterstained with Hoechst (middle and right panels, blue) to show nuclei. Arrows indicate Snail-positive cells. V, Ventricle. Hatched white lines on the left panel indicate the different cortical regions, the cortical plate (CP), the intermediate zone (IZ), the subventricular zone (SVZ), and the ventricular zone (VZ). Scale bar, $20 \mu \mathrm{m}$. E, E12.5 cortical precursors cultured $3 \mathrm{~d}$ and immunostained for Snail (red) and $\beta$ III-tubulin (green), counterstained for Hoechst 33258 (blue). Top, $\beta$ Ill-tubulin-positiveneurons (arrows). Bottom, $\beta$ III-tubulinnegative precursors positive for nuclear Snail (arrowheads). $\boldsymbol{F}$, Western blot of HEK 293 cells cotransfected with a Snail expression construct and a control shRNA (shCon), or one of two Snail shRNAs, Snail shRNA1 (Snail sh1) or Snail shRNA2 (Snail sh2). The blot was reprobed for total ERK protein. G-J, E12 cortical precursors were cotransfected with a plasmid expressing nuclear EGFP and control shRNA (Con) or one of two different Snail shRNAs (Snail sh1 and Snail sh2). G, Fluorescence micrographs of cells transfected with Snail shRNA2, immunostained for EGFP (green) 2 d after transfection. Arrows indicate an EGFP-positive cell with a condensed, apoptotic nucleus, as indicated by Hoechst (blue) staining. Scale bar, $20 \mu \mathrm{m}$. H, Quantification of EGFP-positive cells with condensed apoptotic nuclei in experiments similar to that in G. ${ }^{*} p<0.05$ (ANOVA with Student-Newman-Keuls post hoc analysis). $n=4$ independent experiments. I, J, Quantification of EGFPpositive, CC3-positive cells at 2 and $4 \mathrm{~d}$ after transfection. ${ }^{* *} p<0.01$ (ANOVA with Student-Newman-Keuls post hoc analysis). $n=3$ independent experiments. $K$, Quantification of transfected, $\beta$ III-tubulin-positive neurons ( $\beta$ III + ve), and $\beta \| l$-tubulin-negative precursors ( $\beta$ III-ve) that were positive for CC34 dafter transfection. Also shown are total EGFP-positive, CC3-positive cells in the same experiments (Total). ${ }^{*} p<0.05$ (ANOVA with Student-Newman-Keuls post hoc analysis). ${ }^{* *} p<0.01$ (ANOVA with Student-Newman-Keuls post hoc analysis). $n=3$ independent experiments. L, Quantification of EGFP-positive cells with condensed, apoptotic nuclei $4 \mathrm{~d}$ after transfection with an EGFP plasmid and control or Snail shRNAs, plus a human Snail expression construct (H. Snail) or the empty vector (EV). The graph is normalized relative to control shRNA-transfected cells. ${ }^{*} p<0.05 . n=4$ independent experiments. Error bars indicate SEM. 
A
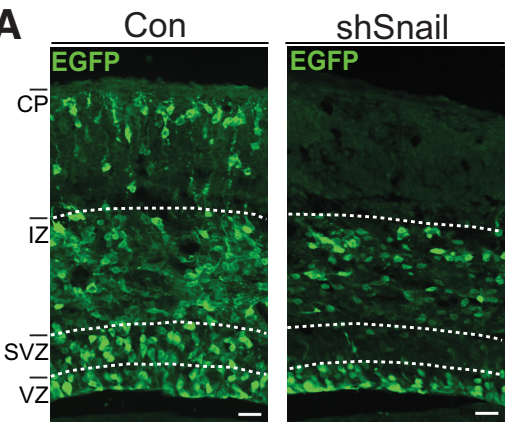

D
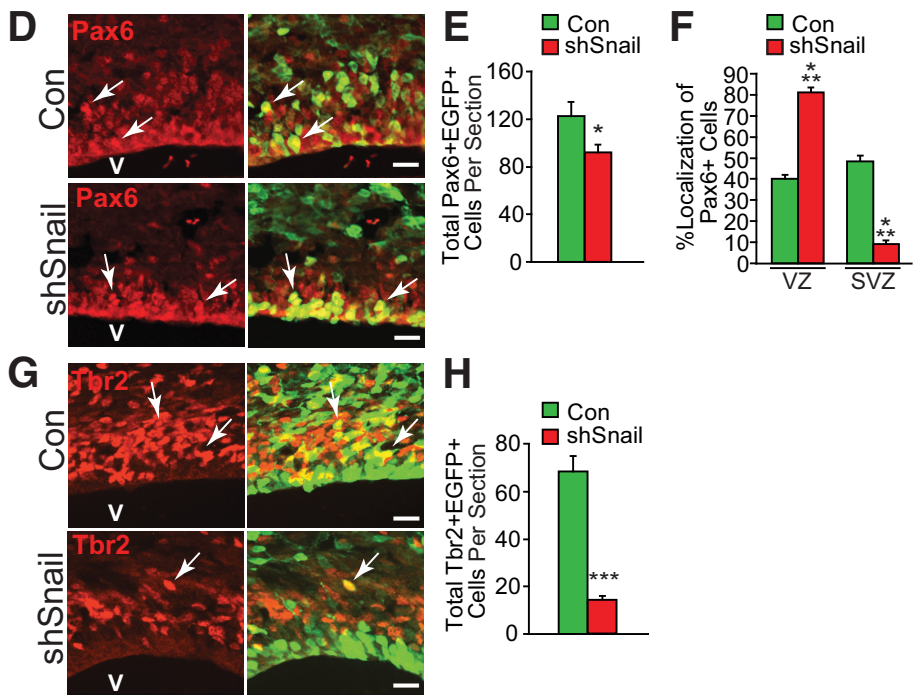

I

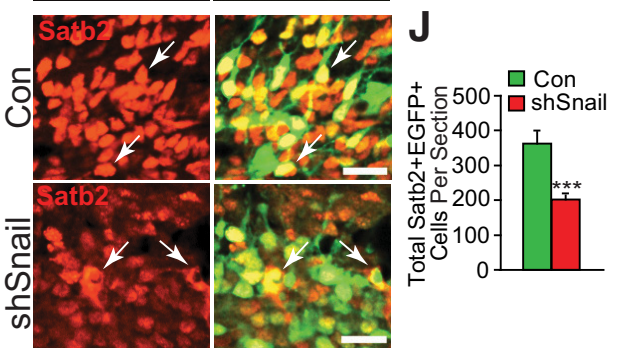

K

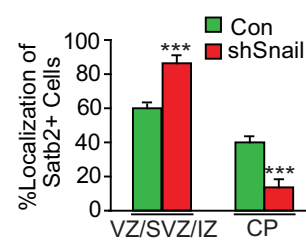

Figure 2. Snail knockdown perturbs cell numbers and location in the embryonic cortex. Murine cortices were electroporated at E13/E14 with a nuclear EGFP expression plasmid and control (Con) or Snail shRNA \#2 (shSnail), and analyzed $3 \mathrm{~d}$ later. $\boldsymbol{A}$, Fluorescence micrographs of coronal sections through E16/E17 cortices immunostained for EGFP (green). Dotted white lines indicate the different cortical regions. Scale bar, $20 \mu \mathrm{m}$. $\boldsymbol{B}$, Quantification of sections as in $\boldsymbol{A}$ for total number of EGFP-positive cells per section. ${ }^{* *} p<0.001 . n=7$ control and 9 Snail shRNA brains. $C$, Quantification of sections as in $\boldsymbol{A}$ for percentage of EGFP-positive cells in different cortical regions. ${ }^{*} p<0.05$. ${ }^{* * *} p<0.001 . n=3$ embryos each. $\boldsymbol{D}$, Confocal micrographs of the VZ/SVZ of coronal cortical sections immunostained for EGFP (green) and Pax6 (red, right panels show the merges). Arrows indicate double-labeled cells. V, Ventricle. Scale bar, $20 \mu \mathrm{m}$. $\boldsymbol{E}, \boldsymbol{F}$, Quantification of sections as in $\boldsymbol{D}$ for total Pax6-positive, EGFP-positive cells per section $(\boldsymbol{E})$, and their relative localization within the VZ versus SVZ $(\boldsymbol{F})$. ${ }^{*} p<0.05 . n=7$ control and 9 Snail shRNA brains. G, Confocal micrographs of the VZ/SVZ immunostained for EGFP (green) and Tbr2 (red, right panels show the merges). Arrows indicate double-labeled cells. Scale bar, $20 \mu \mathrm{m}$. $\boldsymbol{H}$, Quantification of sections as in $\mathbf{G}$ for total Tbr2-positive, EGFP-positive cells per section. ${ }^{* *} p<0.001 . n=4$ embryos each. $I$, Confocal micrographs of the cortical plate immunostained for EGFP (green) and Satb2 (red; right panel shows the merge). Arrows indicate double-labeled cells. Scale bar, $20 \mu \mathrm{m}$. $\boldsymbol{J}, \boldsymbol{K}$, Quantification of sections as in I for total Satb2-positive, EGFPpositive cells per section $(\boldsymbol{J})$, and for their relative location, expressed as a percentage of double-positive cells within the different cortical regions $(\boldsymbol{K}){ }^{* * *} p<0.001 . n=4$ embryos each. Error bars indicate SEM.

spanning the ventricle to the meninges within the same sections, and this proportion was multiplied by the total number of EGFP-positive cells/ section to obtain the total number of marker-positive cells.

Statistics. All data were expressed as the mean plus or minus the SEM and were tested for statistical significance with Student's $t$ tests unless otherwise indicated, in which case they were analyzed with a StudentNeuman-Keuls post hoc ANOVA. Differences were considered significant if $p<0.05$. All tests were performed using Prism 5 (GraphPad).

\section{Results}

Snail is expressed in neural precursors of the embryonic murine cortex

To determine whether Snail regulates mammalian neural precursors, we examined murine radial glial precursors that generate cortical neurons from approximately embryonic day 12 (E12) until birth. RT-PCR analysis showed that Snail mRNA was expressed in the cortex at E11 through E15 (Fig. 1A), as well as in radial precursors and intermediate progenitors that were purified by sorting them from the E13 cortex of mice where EGFP was knocked-in to one allele of the precursor gene sox2 (Hutton and Pevny, 2011) (Fig. $1 A$, bottom right). Western blot analysis with a previously validated Snail-specific antibody (Zhou et al., 2004) showed that Snail protein was also detectable from E11 to postnatal day 1 (P1) (Fig. 1B). Immunostaining with an antibody that recognized Snail but not the related Snail2 (Fig. 1C) showed that at E16/E17 Snail was expressed and nuclear-localized in most cells within the precursor regions of the cortex, the VZ and SVZ and in newly born neurons in the cortical plate (Fig. 1D).

\section{Snail regulates survival in cortical precursor cultures}

To ask whether Snail regulates neural precursor biology, we analyzed E12.5 cortical cultures which, when plated, are comprised of proliferating radial glial precursors that generate newborn neurons in culture (Gauthier-Fisher et al., 2009; Vessey et al., 2012). RT-PCR analysis showed that Snail mRNA was expressed at 1 and $3 \mathrm{~d}$ in these cultures (Fig. 1A, bottom left). Immunostaining showed that Snail protein was detectable in nuclei of newborn neurons expressing the early neuronal marker $\beta$ III-tubulin and in precursors that were negative for this marker (Fig. $1 E$ ).

To ask about the function of Snail, we used two shRNAs targeted to murine Snail mRNA. To test their efficacy, we transfected them into HEK 293 cells with an expression vector for mouse Snail. Western blot analysis 2 d later showed that both shRNAs efficiently knocked down Snail expression (Fig. $1 F)$ and demonstrated the specificity of the Snail antibody that was used for the Western blots. These shRNAs were also efficacious in cortical precursors, as shown by cotransfecting them into E12.5 cultured precursors together with nuclear-localized EGFP. Immunostaining showed that the Snail shRNAs significantly increased the proportion of transfected precursors that expressed low/undetectable levels of Snail (Control shRNA, $18.3 \pm 2.0 \%$; Snail shRNA1, $42.0 \pm 2.2 \%$; Snail shRNA2, $43.3 \pm 5.6 \% ; p>0.01 ; 3$ independent experiments). 
Having established the efficacy of the shRNAs, we asked whether Snail knockdown affected cultured precursor survival by cotransfecting cells with a nuclear EGFP expression plasmid plus control or Snail shRNA. Quantification of EGFPpositive cells with condensed, apoptotic nuclei $2 \mathrm{~d}$ later showed that $\sim 4 \%$ of control shRNA-transfected cells had apoptotic nuclei and this was increased twofold to threefold in cells transfected with the Snail shRNAs (Fig. 1G,H). Similar results were obtained by quantification of the apoptotic marker cleaved caspase-3 (CC3) at either 2 or $4 \mathrm{~d}$ after transfection (Fig. $1 I, J)$. We asked whether these dying cells were precursors or neurons by triplelabeling transfected cultures for EGFP, CC3, and $\beta$ III-tubulin. Snail knockdown significantly increased the apoptosis of both $\beta$ III-tubulin-positive neurons and $\beta$ III-tubulin-negative precursors (Fig. $1 K$ ).

To ensure the specificity of this shRNAmediated apoptosis, we performed rescue experiments. Cultured precursors were cotransfected with EGFP and one of the two Snail shRNAs with or without a plasmid expressing human Snail, which does not contain the targeted sequences. Quantification of condensed, apoptotic nuclei $4 \mathrm{~d}$ later showed that human Snail expression significantly rescued the Snail shRNAmediated apoptosis (Fig. $1 L$ ). Thus, Snail is important for survival of radial precursors and their newborn neuronal progeny.

\section{Snail knockdown perturbs the number and location of developing cortical precursors and neurons}

To ask whether Snail also regulates cortical development in vivo, we in utero electroporated E13/E14 cortices with a nuclear EGFP expression plasmid and the more efficacious Snail shRNA (shRNA2). This approach transfects radial precursors that line the ventricles (Gauthier et al., 2007). Many of these precursors differentiate into neurons in the VZ/SVZ over the subsequent $4 \mathrm{~d}$, and these newborn neurons migrate through the intermediate zone (IZ) into the cortical plate. Immunostaining $3 \mathrm{~d}$ after electroporation (Fig. 2A) showed that there were only half as many total EGFP-positive cells in cortices electroporated with Snail versus control shRNAs (Fig. 2B) and that these cells were mislocalized, with significantly fewer in the SVZ and cortical plate and significantly more in the VZ and IZ (Fig. $2 A, C$ ). To ask whether all cell types were equally reduced in number, we initially analyzed the radial precursor marker Pax6 (Fig. $2 D)$. In cortices electroporated with Snail
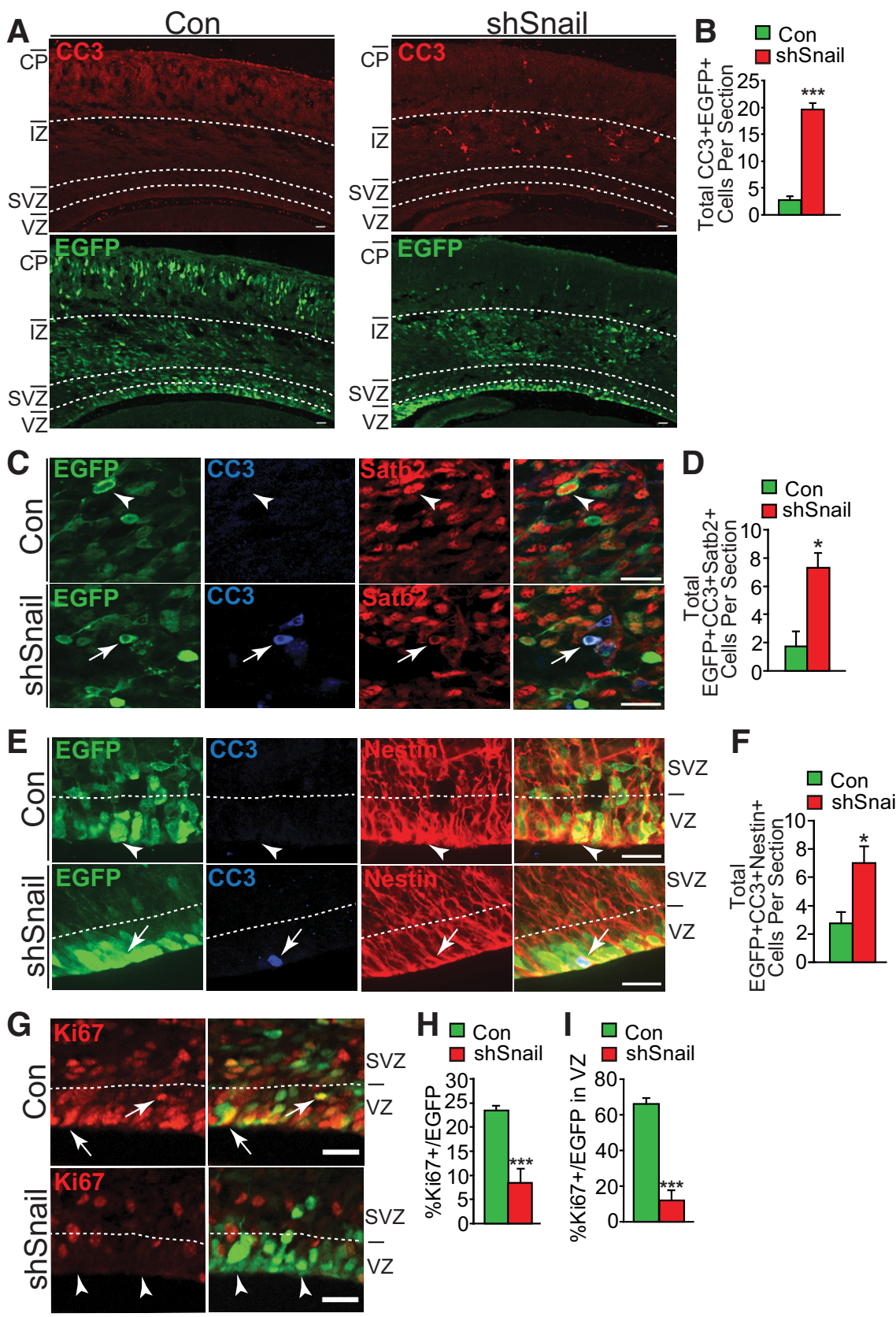

Figure 3. Snail knockdown enhances cell death and decreases radial precursor proliferation in the embryonic cortex. E13/E14 murine cortices were electroporated with nuclear EGFP and a control shRNA (Con) or Snail shRNA \#2 (shSnail), and analyzed $3 \mathrm{~d}$ later at E16/E17. A, Fluorescence micrographs of coronal cortical sections immunostained for EGFP (green) and CC3 (red). White lines indicate the different cortical regions. Scale bar, $20 \mu \mathrm{m}$. B, Quantification of sections as in $\boldsymbol{A}$ for total CC3-positive, EGFP-positive cells per section. ${ }^{* * *} p<0.001 . n=6$ control and 5 Snail shRNA brains. $C$, Confocal micrographs of electroporated cortices showing the cortical plate immunostained for EGFP (green), CC3 (blue), and Satb2 (red; right panels show the merges). Arrows indicate triple-labeled cells. Arrowheads indicate EGFP-positive, Satb2-positive cells that are CC3-negative. Scale bar, $20 \mu \mathrm{m}$. D, Quantification of sections as in C for total EGFP-positive, CC3-positive, Satb2-positive neurons per section. ${ }^{*} p<0.05 . n=4$ control and 5 Snail shRNA brains. $\boldsymbol{E}$, Confocal micrographs of electroporated cortices showing the VZ/SVZ immunostained for EGFP (green), CC3 (blue), and nestin (red; right panels show the merges). Arrows indicate triple-labeled cells. Arrowheads indicate EGFP-positive, nestin-positive cells that are CC3-negative. Hatched white lines indicate the border between the VZ and SVZ. Scale bar, $20 \mu \mathrm{m}$. F, Quantification of sections as in $\boldsymbol{E}$ for total EGFP-positive, CC3-positive, nestin-positive precursors per section. ${ }^{*} p<0.05 . n=4$ control and 5 Snail shRNA brains. G, Confocal micrographs of the VZ/SVZ immunostained for EGFP (green) and Ki67 (red; right panels show the merges). Arrows and arrowheads indicate EGFP-positive cells that are positive and negative for Ki67, respectively. Hatched white lines indicate the border between the VZ and SVZ. Scale bar, $20 \mu \mathrm{m}$. $\boldsymbol{H}, \boldsymbol{I}$, Quantification of sections as in $\boldsymbol{G}$ for the proportion of EGFP-positive cells that were Ki67-positive in the entire cortex $(\boldsymbol{H})$ or in the VZ only $(\boldsymbol{I}) .{ }^{* * *} p<0.001$. $n=3$ embryos each. Error bars indicate SEM. 

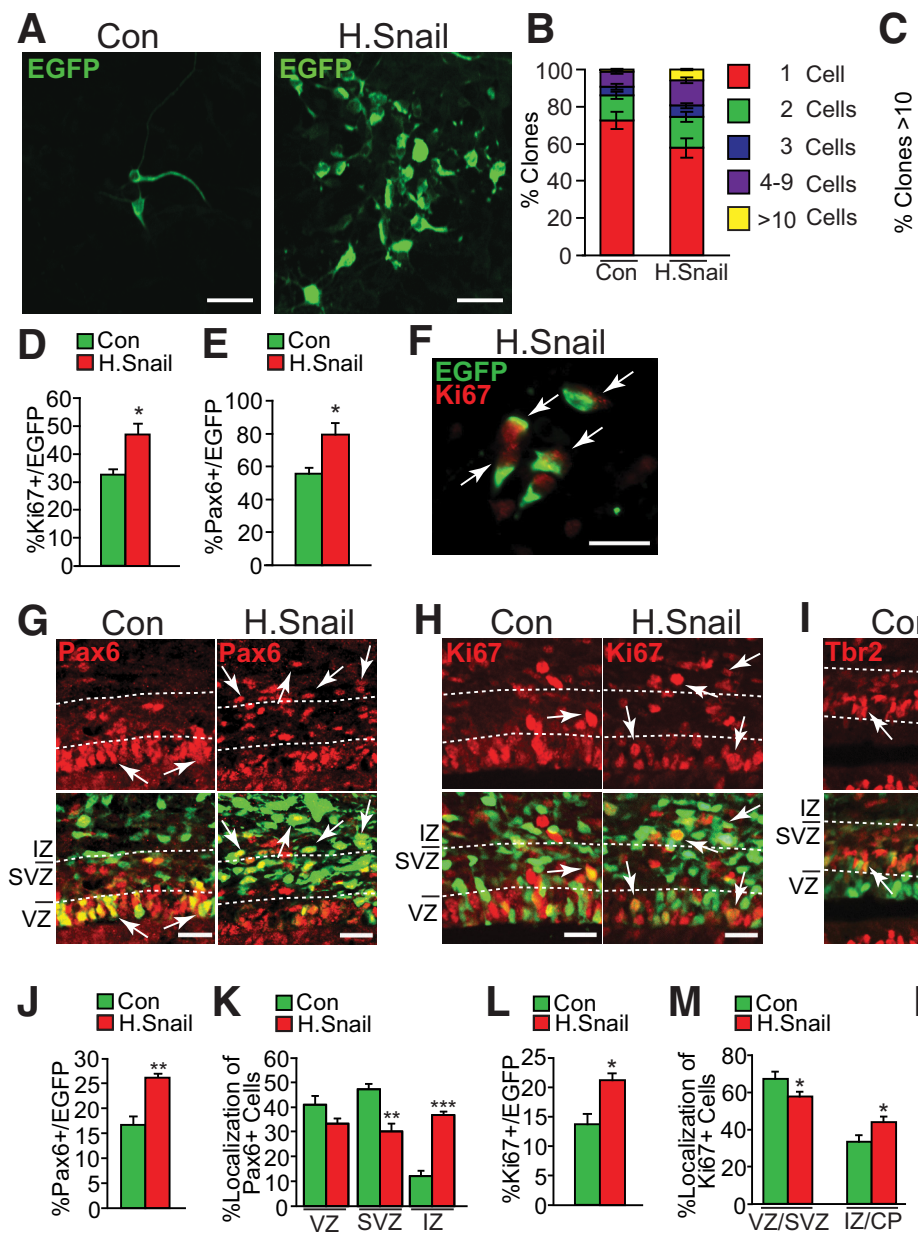

Figure 4. Snail overexpression enhances radial precursor self-renewal. $\boldsymbol{A}-\boldsymbol{F}, \mathrm{E} 12$ cortical precursors were cotransfected with PB-EGFP and PBase, and either a human Snail construct (H. Snail) or the empty vector (Con). $\boldsymbol{A}$, Representative small (left) and large (right) EGFP-positive (green) clones. Scale bar, $20 \mu \mathrm{m}$. B, Quantification of clone size in three independent experiments as in $\boldsymbol{A}$. $\boldsymbol{C}$, Quantification of EGFP-positive clones that contained more than 10 cells. ${ }^{* *} p<0.01 . n=3$ independent experiments. $\boldsymbol{D}, \boldsymbol{E}$, Quantification of EGFP-positive, Ki67-positive $(\boldsymbol{D})$ or Pax6-positive cells $(\boldsymbol{E}) .{ }^{*} p<0.05 . n=3$ independent experiments. $\boldsymbol{F}$, Precursors immunostained $4 \mathrm{~d}$ after transfection for EGFP (green) and Ki67 (red) with arrows denoting double-labeled cells. Scale bar, $20 \mu \mathrm{m}$. G-N, E13/E14 cortices were electroporated with a nuclear EGFP plasmid plus a control plasmid (Con) or a human Snail expression construct (H. Snail), and analyzed 3 d later. G-I, Confocal micrographs of the VZ/SVZ immunostained for EGFP (green) and Pax6 $(\mathbf{G})$, Ki67 $(\boldsymbol{H})$, or Tbr2 (I; all red, bottom panels show the merges). White lines indicate the different regions of the cortex. Arrows indicate double-labeled cells. Scale bar, $20 \mu \mathrm{m}$. J, $\boldsymbol{K}$, Quantification of sections as in $\mathbf{G}$ for the percentage of Pax6-positive, EGFP-positive cells relative to total EGFP-positive cells $(\boldsymbol{J})$, or for the relative location of Pax6-positive, EGFP-positive cells in the VZ, SVZ, and IZ $(\boldsymbol{K}) .{ }^{* *} p<0.01$. ${ }^{* * *} p<0.001 . n=4$ embryos each. $\boldsymbol{L}, \boldsymbol{M}$, Quantification of sections as in $\boldsymbol{H}$ for the percentage of Ki67-positive, EGFP-positive cells relative to total EGFP-positive cells $(\boldsymbol{L})$, or for the relative location of Ki67-positive, EGFP-positive cells in the VZ/SVZ and IZ/cortical plate $(\boldsymbol{M}) .{ }^{*} p<0.05$ ( $n=4$ embryos each). $\boldsymbol{N}$, Quantification of sections as in $I$ for the percentage of EGFP-positive cells that are double-labeled for Tbr2. $p>0.05 . n=4$ embryos each. Error bars indicate SEM.

shRNA, radial precursor numbers were decreased (Fig. 2E), and their location was perturbed, with a large proportion of the EGFP-positive, Pax6-positive nuclei close to or lined-up at the apical, ventricular surface (Fig. $2 D, F$ ). This aberrant radial precursor localization likely accounts for the increased proportion of total EGFP-positive cells in the VZ (Fig. 2C).

To ask about intermediate progenitors, we immunostained similar sections for Tbr2 (Fig. 2G). In contrast to radial precursors, after Snail knockdown Tbr2-positive intermediate progenitors were still located in the SVZ (Fig. 2G), but their total numbers were decreased by more than fourfold (Fig. $2 H$ ).

Finally, we asked about neurons by immunostaining cortices for Satb2, which is expressed in the vast majority of EGFPpositive neurons born over the time frame of our in utero elec-
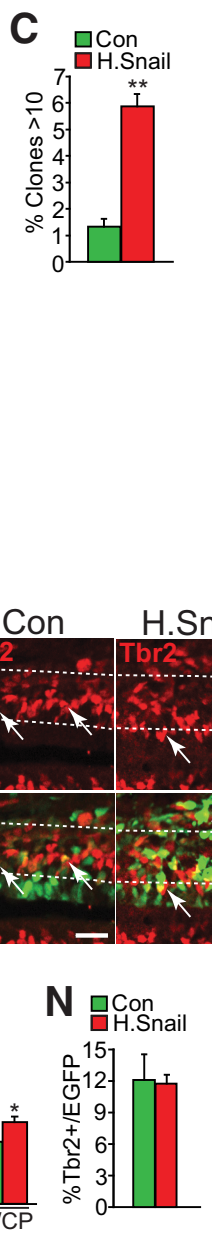

troporation experiments (Tsui et al., 2013). Snail knockdown caused an almost twofold decrease in total newborn neurons (Fig. 2I,J), and these neurons were mislocalized, with proportionately fewer in the cortical plate (Fig. $2 K$ ). Thus, Snail knockdown decreases all three cell types and perturbs the localization of radial precursors and neurons.

Snail knockdown decreases cell survival and inhibits radial precursor proliferation in the embryonic cortex The Snail knockdown-mediated decrease in EGFP-positive cells in vivo could be the result of decreased survival, as we saw in culture, and/or of decreased proliferation. To distinguish these possibilities, we immunostained sections for EGFP and CC3 $3 \mathrm{~d}$ after electroporation (Fig. 3A). As we have previously shown (Bartkowska et al., 2007), control shRNA-treated cortices contained very few EGFP-positive, CC3positive cells, $\sim 2-3$ per section (Fig. $3 B$ ). In contrast, in Snail shRNA-electro porated cortices, there were approximately 20 double-labeled cells per section, and these were scattered throughout the cortex (Fig. $3 A, B$ ). To define these cells, we triple-labeled sections for EGFP, CC3, and either Satb2 or the precursor marker nestin (Fig. 3C,E). Quantification showed that Snail knockdown enhanced the apoptosis of Satb2-positive neurons and nestin-positive precursors compared with control shRNA-treated cortices (Fig. $3 D, F)$.

To ask whether Snail also affected precursor proliferation, we immunostained similar sections for EGFP and the proliferation marker Ki67 (Fig. 3G). Snail knockdown caused a twofold to threefold decrease in the proportion of EGFPpositive cells that were Ki67-positive (Fig. $3 \mathrm{H})$ and strikingly showed that almost none of the EGFP-positive radial precursors within the $\mathrm{VZ}$ were proliferating (Fig. $3 H, I)$. Thus, Snail knockdown robustly decreases radial precursor proliferation at the same time it causes their nuclei to localize within the VZ.

\section{Overexpression of Snail increases radial precursor self-} renewal and causes them to move away from the VZ.

These data indicate that, in addition to promoting cell survival, Snail is necessary for radial precursors to proliferate and selfrenew. To ask whether Snail is sufficient to enhance precursor self-renewal, we performed clonal analysis in culture, using the piggybac (PB) transposon. In this system, a plasmid encoding the $\mathrm{PB}$ transposase is cotransfected with a plasmid encoding EGFP flanked by inverted terminal repeats; when the transposase is expressed, this leads to genomic integration of the flanked EGFP sequence (Gallagher et al., 2013; Tsui et al., 2013). E12.5 cortical precursors were cotransfected at low efficiency with a Snail ex- 
pression construct or the control vector, together with plasmids encoding $\mathrm{PB}$ transposase and the PB EGFP reporter. Three days later, cultures were immunostained for EGFP (Fig. 4A) and Pax6 (data not shown) or Ki67 (Fig. 4F). This analysis showed that Snail overexpression caused a significant increase in clone size (Fig. $4 A, B$ ) that was particularly obvious when analyzing clones of 10 cells or greater in size (Fig. 4C). This was not attributable to differences in cell survival because the proportion of cells with condensed, apoptotic nuclei was similar in both conditions $(8.3 \pm 1.83$ for Snail overexpression vs $7.9 \pm 0.6$ for controls; $p>0.05, n=3$ experiments). Instead, there were significant increases in the proportions of proliferating, Ki67-positive, EGFP-positive cells (Fig. 4D) and Pax6positive, EGFP-positive radial precursors (Fig. 4E). Moreover, most of the small one and two cell clones were composed of newborn neurons, whereas the larger clones, which were increased in the Snail overexpression condition, were predominantly composed of Ki67-positive, Pax6positive radial precursors (Fig. $4 F$ ).

We next asked whether Snail overexpression enhanced radial precursor proliferation and self-renewal in vivo by electroporating plasmids encoding Snail and EGFP into the E13/E14 cortex. As a control, we used the empty expression vector plus the same EGFP plasmid. Analysis by immunostaining for Pax6 3 d later (Fig. 4G) demonstrated that Snail overexpression increased the proportion of transfected radial precursors from $16 \%$ to $26 \%$ (Fig. $4 \mathrm{~J}$ ) and changed their location. In controls almost all Pax6positive nuclei were found within the $\mathrm{VZ}$ and SVZ, but with Snail overexpression many moved away from the VZ and were located within the IZ (Figs. $4 G, K$ ). Consistent with these data, immunostaining for Ki67 (Fig. 4H) showed an increase in proliferating cells (Fig. 4L) and demonstrated that proportionately more of these were located outside of the VZ/SVZ (Fig. $4 M)$. In contrast to these changes in radial precursors, the proportion of Tbr2positive intermediate progenitors was not significantly altered by Snail overexpression (Fig. 4I,N). Thus, Snail overexpression increases radial precursor self-renewal.

Snail selectively regulates cortical cell survival by a p53-dependent mechanism These gain- and loss-of-function studies indicate that Snail regulates neural precursor survival and proliferation/self-renewal. Because the C. elegans ortholog of Snail regulates precursor sur-
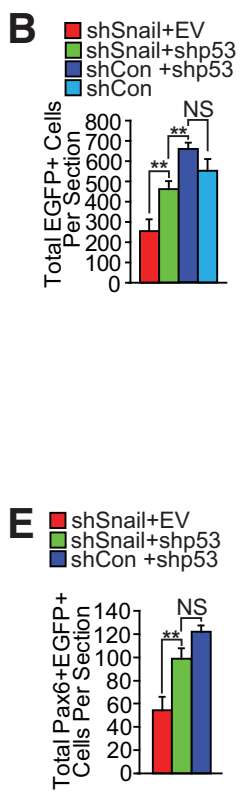

$\mathrm{J}$

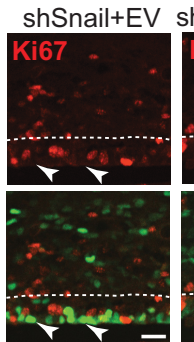

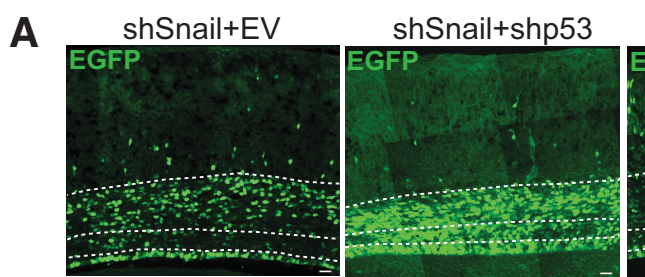
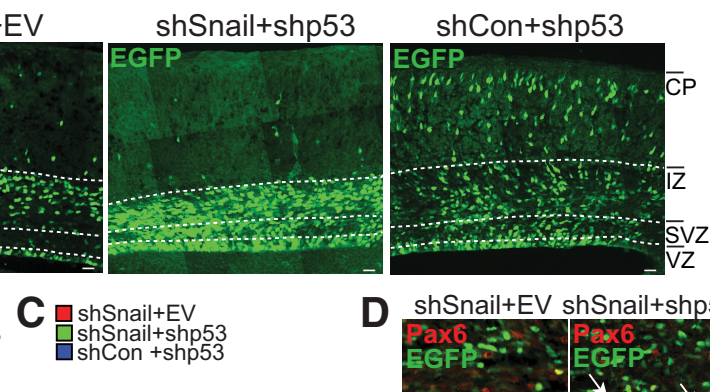

D

shSnail+EV shSnail+shp53
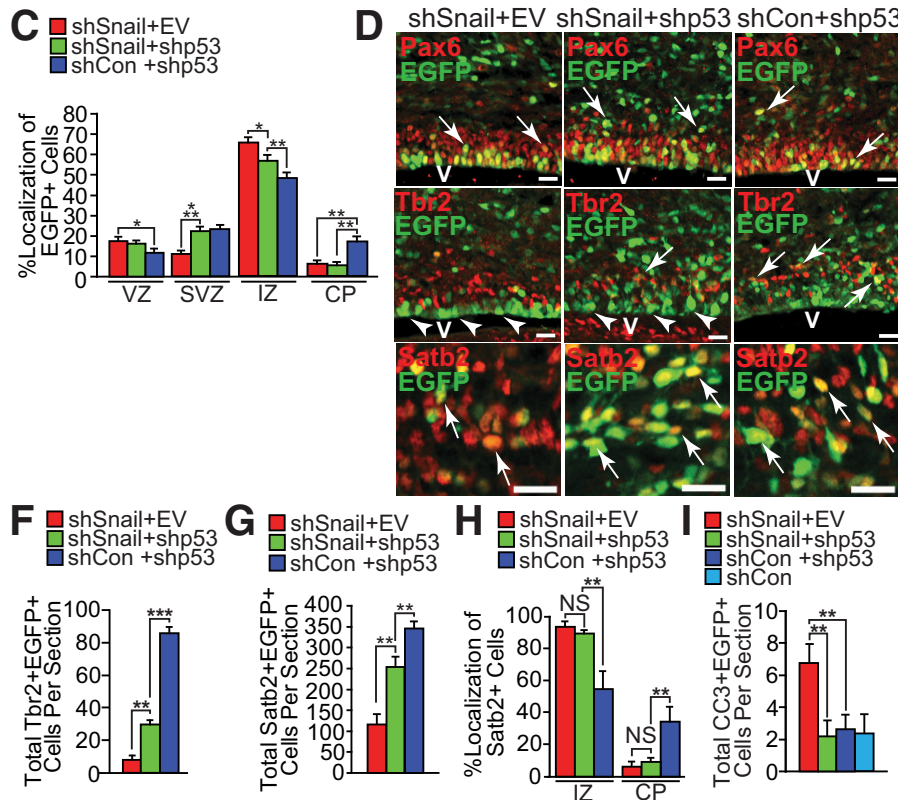

口shSnail+EV
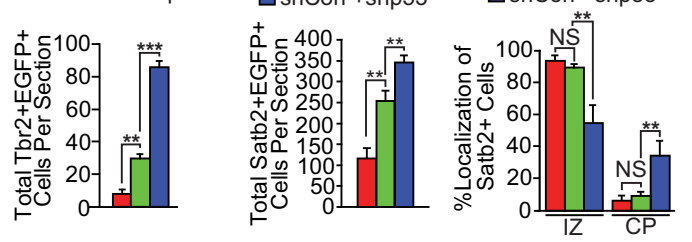

shSnail+shp53 shCon +shp53
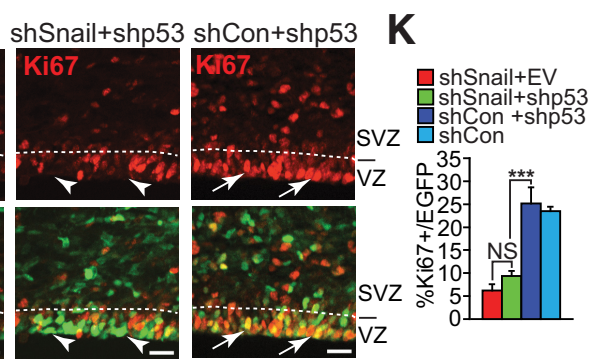

L

Figure 5. Coincident 553 knockdown rescues the deficits in cell numbers and cell survival caused by Snail knockdown. E13/E14 cortices were electroporated with nuclear EGFP and control shRNA (Con) or Snail shRNA2 (shSnail), plus either a p53 shRNA (shp53) or the empty vector (EV), and analyzed at E16/E17. A, Coronal cortical sections immunostained for EGFP (green). White lines indicate cortical regions. Scale bar, $20 \mu \mathrm{m}$. B, Quantification of sections as in $\boldsymbol{A}$ for total EGFP-positive cells per section. ${ }^{* *} p<0.01$ (ANOVA with Student-NewmanKeuls post hoc analysis). $n=4$ embryos each. $C$, Quantification of coronal cortical sections as in $A$ for the proportion of EGFP-positive cells in the different regions of the embryonic cortex. ${ }^{*} p<0.05$ (ANOVA with Student-Newman-Keuls posthocanalysis). ${ }^{* *} p<0.01$ (ANOVA with Student-Newman-Keuls post hoc analysis). ${ }^{* * *} p<0.001$ (ANOVA with Student-Newman-Keuls post hoc analysis). $n=3$ embryos each. D, Confocal micrographs of the VZ/SVZ (top and middle) or cortical plate (bottom) immunostained for EGFP (green) and Pax6 (top), Tbr2 (middle), or Satb2 (bottom; all in red). Arrowheads indicate cells positive for EGFP only. Arrows indicate double-labeled cells. V, Ventricle. Scale bar, $20 \mu \mathrm{m}$. $\boldsymbol{E}-\boldsymbol{G}$, Quantification of sections as in D for total EGFP-positive cells that were also positive for Pax6 (E), Tbr2 $(\boldsymbol{F})$, or Satb2 (G). ${ }^{* *} p<0.01$ (ANOVA with Student-Newman-Keuls post hoc analysis). ${ }^{* * *} p<0.001$ (ANOVA with Student-Newman-Keuls post hoc analysis). NS $=p>0.05$ (ANOVA with Student-Newman-Keuls posthoc analysis). $n=3$ or 4 embryos each. $\boldsymbol{H}$, Quantification of sections as in $\boldsymbol{D}$ for the relative localization of Satb2-positive, EGFP-positive cells. ${ }^{* *} p<0.01$ (ANOVA with Student-Newman-Keuls post hoc analysis). NS $=p>0.05$ (ANOVA with Student-Newman-Keuls post hoc analysis). $n=3$ embryos each. $I$, Quantification of sections double-labeled for EGFP and CC3, for total EGFP-positive, CC3-positive cells per section. ${ }^{* *} p<0.01$ (ANOVA with Student-Newman-Keuls post hoc analysis). $n=4$ embryos each. $J$, Confocal micrographs of the VZ/SVZ immunostained for EGFP (green) and Ki67 (red; bottom panels show merges). Arrows and arrowheads indicate EGFP-positive cells that are positive and negative for Ki67, respectively. Hatched white lines indicate the border between the VZ and SVZ. Scale bar, $20 \mu \mathrm{m} . \boldsymbol{K}, \boldsymbol{L}$, Quantification of sections as in $J$ for the relative proportion of EGFP-positive cells that are also Ki67-positive in the entire cortex $(\boldsymbol{K})$ or in the VZ only $(\boldsymbol{L}) .{ }^{* *} p<0.01$ (ANOVA with Student-NewmanKeuls post hoc analysis). ${ }^{* * *} p<0.001$ (ANOVA with Student-Newman-Keuls post hoc analysis). NS $=p>0.05$ (ANOVA with StudentNewman-Keuls post hoc analysis). $n=4$ embryos each. Error bars indicate SEM.

vival by repressing a $\mathrm{BH} 3$ protein-dependent pathway (Thellmann et al., 2003; Hatzold and Conradt, 2008), and because BH3 proteins (e.g., Puma and Noxa) are regulated by p53 in mammalian neural precursors (Cancino et al., 2013), we asked whether 
A
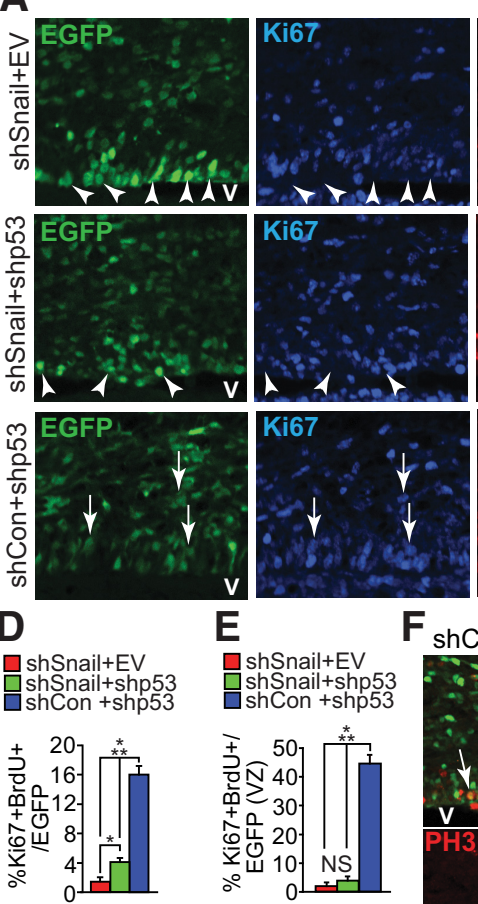

\section{$\mathbf{F}$}

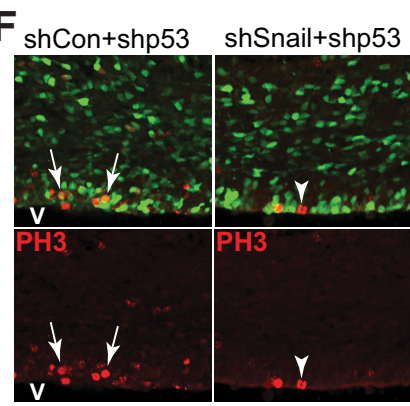

.

D

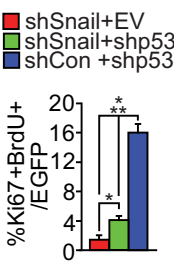

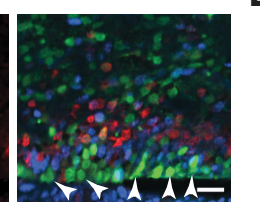

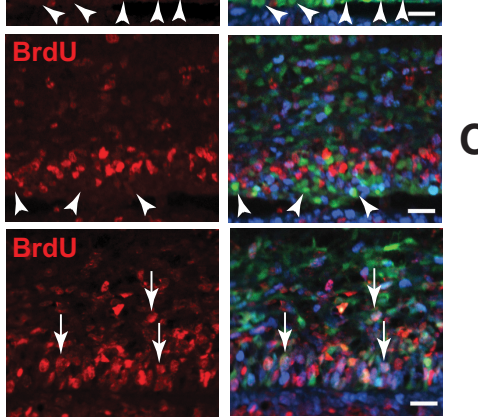

G

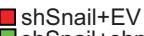

shSnail+shp53

$\square$ shCon + shp

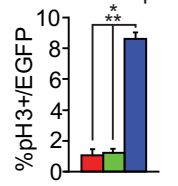

Figure 6. Snail knockdown locks radial precursors out of the cell cycle independent of p53-mediated effects on cell survival. E13/E14 cortices were electroporated with nuclear EGFP and control shRNA (Con) or Snail shRNA2 (shSnail), plus either a p53 shRNA (shp53) or the empty vector (EV). Two days later, pregnant mothers were treated with BrdU, and embryos were analyzed $1 \mathrm{~d}$ later atE16/E17.A, Confocal micrographs of the VZ/SVZ immunostained for EGFP (green), Ki67 (blue), and BrdU (red; right panels show merges). Arrows indicate triple-labeled cells. Arrowheads indicate EGFP-positive cells in the VZ that are negative for Ki67 and BrdU.V, Ventricle. Scale bar, $20 \mu \mathrm{m}$. $\boldsymbol{B}$, C, Quantification of sections as in $\boldsymbol{A}$ for the proportion of EGFP-positive cells that are also BrdU-positive either in the entire cortex $(\boldsymbol{B})$ or in the $\mathrm{VZ}(\boldsymbol{C}){ }^{* * *} p<0.001$ (ANOVA with Student-Newman-Keuls post hoc analysis). $n=3$ embryos each. $\boldsymbol{D}, \boldsymbol{E}$, Quantification of sections as in $\boldsymbol{A}$ forKi67-positive, BrdU-positive, EGFP-positivecells relativeto totalEGFP-positivecells eitherintheentirecortex (D) orintheVZ(E). ${ }^{*} p<0.05$ (ANOVA with Student-Newman-Keuls posthoc analysis). ${ }^{* * *} p<0.001$ (ANOVA with Student-Newman-Keuls posthoc analysis). NS $=p>0.05$ (ANOVA with Student-Newman-Keuls posthoc analysis). $n=3$ embryos each. $\boldsymbol{F}$,Confocal micrographs of the VZ/SVZ immunostained for EGFP (green) and phospho-histoneH3 (PH3; red). Arrows and arrowheads indicateEGFP-positive cells that are positive and negative for pH3, respectively. Scale bar, 20 $\mu \mathrm{m} . \mathbf{G}$, Quantification of sections as in $\boldsymbol{F}$ for the relative proportion of EGFP-positive cells that are also positive for $\mathrm{pH} 3$. $^{* *} p<0.001$ (ANOVA with Student-Newman-Keuls posthocanalysis). $n=3$ embryos each. Error bars indicate SEM.

coincident knockdown of p53 could rescue any of the Snail knockdown phenotypes. We first analyzed p53 knockdown alone, electroporating cortices with EGFP and a p53 shRNA we and others have previously characterized (Brummelkamp et al., 2002; Dugani et al., 2009). A comparison between cortices electroporated with p53 versus control shRNAs (Fig. 5A,B) showed that p53 knockdown did not significantly alter the number or location of EGFP-positive cells, nor did it affect the proportions of transfected, Pax6-positive radial precursors, Tbr2-positive intermediate progenitors, or Satb2-positive neurons $(p>0.05$ for all parameters; $n=$ at least 3 embryos each). Moreover, p53 knockdown did not affect the number of electroporated CC3positive apoptotic cells, or proliferating Ki67-positive cells $(p>$ 0.05 for both parameters; $n=$ at least 3 embryos each).

Because p53 knockdown did not affect normal development, we asked whether it could rescue the Snail knockdown phenotypes, electroporating E13/E14 embryos with an EGFP plasmid and Snail shRNA with or without p53 shRNA. Analysis $3 \mathrm{~d}$ after electroporation showed that concomitant p53 knockdown rescued, in large part, the Snail shRNA-mediated decrease in total EGFP-positive cells (Fig. $5 A, B$ ). However, the aberrant cell localization was not rescued (Fig. $5 A, C$ ).
B $\square$ shSnail+EV $\square$ shSnail+shp53

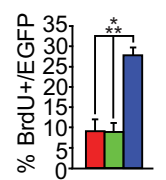

C

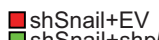

shSnail+shp53

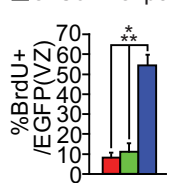

To ask whether p53 knockdown rescued all cell types equally, we analyzed Pax6-, Tbr2-, and Satb2-positive cells (Fig. 5D). p53 knockdown almost completely rescued the Snail shRNA-mediated decreases in radial precursors and neurons (Fig. $5 E, G$ ), but it only modestly rescued intermediate progenitors (Fig. $5 F$ ). Moreover, p53 knockdown did not rescue the Snail shRNA-mediated alterations in location of neurons (Fig. $5 \mathrm{H}$ ).

We next asked whether p53 knockdown rescued cell numbers by altering cell death or proliferation. Immunostaining showed that p53 knockdown completely rescued the increase in apoptotic, CC3positive cells caused by Snail knockdown (Fig. 5I) but that it had no effect on the Snail knockdown-mediated decrease in proliferating, Ki67-positive cells (Fig. $5 \mathrm{~J}, K)$. This was particularly evident in the VZ (Fig. $5 L$ ); $\sim 40-50 \%$ of electroporated radial precursors in the control VZ were Ki67-positive, and this was reduced to 15$20 \%$ after Snail knockdown with or without coincident p53 knockdown. Thus, p53 knockdown selectively rescues the apoptosis caused by Snail knockdown and, in so doing, largely rescues the total numbers of radial precursors and neurons and, to a lesser degree, intermediate progenitors.

\section{Snail knockdown locks radial precursors out of the cell cycle in a p53-independent fashion}

The finding that p53 knockdown rescued the Snail shRNA-mediated apoptosis provided us the opportunity to define the radial precursor proliferation deficit without the confound of cell death. We therefore analyzed an array of cell cycle parameters in cortices coelectroporated with both Snail and p53 shRNAs. To do this, we performed in utero electroporation at E13/E14, administered BrdU $2 \mathrm{~d}$ later, and analyzed cortices $1 \mathrm{~d}$ later. Immunostaining showed that, in cortices electroporated with the p53 shRNA alone, almost $30 \%$ of the total EGFP-positive cells and $50-60 \%$ of those in the VZ had incorporated BrdU (Fig. 6A-C). In contrast, in cortices electroporated with Snail shRNA with or without p53 shRNA, only $9 \%$ of total EGFP-positive cells, and almost none of those in the VZ had incorporated BrdU (Fig. 6A-C).

We also quantified the precursor proliferation index by triplelabeling sections for EGFP, BrdU, and Ki67, which is expressed in all stages of the cell cycle (Fig. 6A). In cortices electroporated with only p53 shRNA, $16 \%$ of total EGFP cells, and almost $45 \%$ of EGFP-positive radial precursors in the VZ were positive for both BrdU and Ki67 (Fig. 6D,E). In contrast, in cortices electroporated with Snail shRNA with or without p53 shRNA, these numbers were reduced to $\sim 3 \%$ and $2 \%$, respectively (Fig. $6 D, E$ ). Thus, in controls, more than half of the cells that had incorporated BrdU were still proliferating $1 \mathrm{~d}$ later, whereas after Snail knockdown, even those few cells that had incorporated BrdU on day 2 were out of the cell cycle $1 \mathrm{~d}$ later. 
Radial precursor nuclei move between the $\mathrm{VZ}$ and $\mathrm{SVZ}$ as they proliferate, and they undergo $G_{2}$ and mitosis when they are most proximal to the apical VZ (Dehay and Kennedy, 2007; Salomoni and Calegari, 2010). Our BrdU studies and our data showing that $>80 \%$ of Pax6positive nuclei are located in the $\mathrm{VZ}$ after Snail knockdown suggest that these radial precursors might be aberrantly locked out of the cell cycle at $G_{2}$ or $M$. We therefore immunostained cortical sections for phospho-histone $\mathrm{H} 3$ ( $\mathrm{pH} 3$ ), which is expressed during $G_{2}$ and $M$. This analysis showed that, in cortices electroporated with p53 shRNA alone, $\sim 8 \%$ of the EGFP-positive cells were $\mathrm{pH} 3$-positive (Fig. $6 F, G$ ), consistent with our previous data (Gauthier-Fisher et al., 2009). Snail knockdown decreased this number to $1 \%$, and this was unaffected by coincident p53 knockdown (Fig. 6F,G). Thus, Snail knockdown aberrantly locks radial precursors out of the cell cycle, to the point where they no longer express proteins associated with actively cycling cells.

\section{The Snail target Cdc25b rescues the} p53-independent precursor phenotypes caused by Snail knockdown

In Drosophila, the neuroblast deficits caused by loss of the Snail family have largely been attributed to inscuteable, but the Snail target string/Cdc25 has also been implicated (Ashraf and Ip, 2001; Southall and Brand, 2009). Because Cdc25b is a cell cycle phosphatase that regulates the $\mathrm{G}_{2} / \mathrm{M}$ transition in mammalian cells (Boutros et al., 2007), we asked whether it might account for the Snail shRNA-mediated proliferation deficits. Immunostaining of E12.5 cortical precursor cultures showed that Cdc25b was expressed in Sox2-positive precursors, where it was largely localized to the nucleus, with some detectable in the cytoplasm (Fig. 7A). Cdc25b immunoreactivity was also detectable in nuclei of most cells within the E16 VZ/SVZ (Fig. 7B). Because Cdc25b is expressed in cortical precursors, we asked whether it is regulated by Snail. Cultured E12.5 precursors were transfected with either the Snail shRNA or the Snail expression construct and $2 \mathrm{~d}$ later were immunostained for Cdc25b (Fig. 7C). Snail knockdown decreased the proportion of transfected cells that expressed medium/high Cdc25b levels and increased those with no/low detectable expression (Fig. 7C,D). In contrast, overexpression of Snail had the converse effect, increasing cells with medium/high Cdc25b levels, and decreasing those with no/ low expression (Fig. 7C,D). Thus, Snail regulates Cdc25b expression in cortical precursors.

Because Snail knockdown decreases Cdc25b levels, we asked whether Snail knockdown-mediated precursor phenotypes could be rescued by ectopic expression of Cdc25b. Initially, we characterized the effects of increasing Cdc25b by itself. E13/E14 cortices were electroporated with expression plasmids for nuclear EGFP
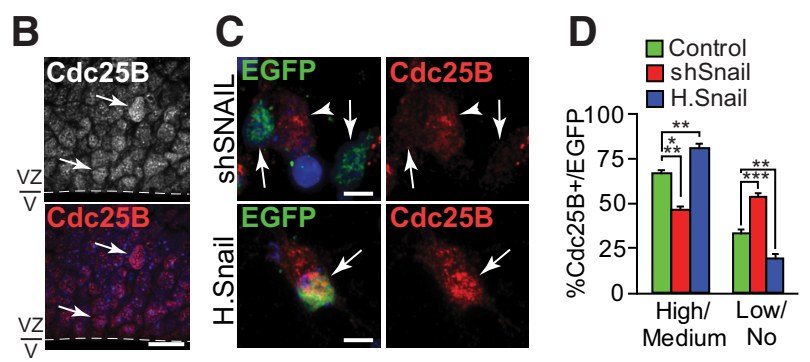

$\mathrm{F}$

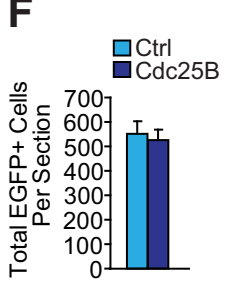

G
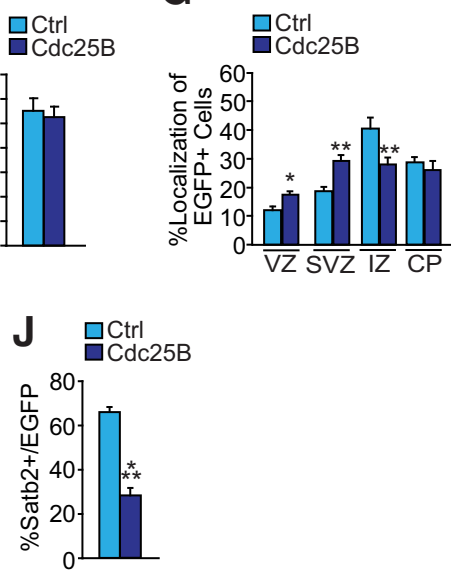

Figure 7. Cdc25b regulates radial precursor development. $\boldsymbol{A}$, Cultured cortical precursors immunostained for Sox2 (green) and Cdc25b (red), counterstained with Hoechst 33258 (blue; bottom right panel shows the merge). $\boldsymbol{B}$, Confocal micrographs of the

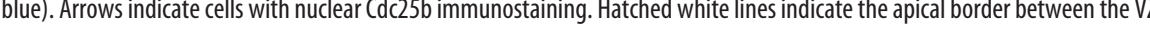
shown in ${ }^{* *} p<0.01$ (ANOVA with Student-Newman-Keuls post hoc analysis) ${ }^{* * *} p<0.001$ (ANOVA with Student-NewmanKeuls post hoc analysis). $n=3$ each. $\boldsymbol{E}-\boldsymbol{J}, \mathrm{E} 13 / \mathrm{E} 14$ cortices were electroporated with a nuclear EGFP plasmid and a Cdc25b (W. White lines indicate cortical regions. Scale bar, $20 \mu \mathrm{m}$. $\boldsymbol{F}, \mathbf{G}$, Quantification of sections as in $\boldsymbol{E}$ for total number $(\boldsymbol{F})$ and relative location $(\boldsymbol{G})$ of EGFP-positive cells. ${ }^{*} p<0.05$. ${ }^{* *} p<0.01 . n=3$ embryos each. $\boldsymbol{H}-\boldsymbol{J}$, Quantification of sections as in $\boldsymbol{E}$ immunostained for EGFP and Pax6 $(\boldsymbol{H})$, Tbr2 $(\boldsymbol{I})$, or Satb2 $(\boldsymbol{J})$, showing the proportion of EGFP-positive, marker-positive cells relative to total EGFP-positive cells. ${ }^{* *} p<0.01 .{ }^{* * *} p<0.001 . n=3$ embryos each.

and mouse Cdc25b and analyzed 3 d later. The total number of EGFP-positive cells was unchanged by Cdc25b overexpression (Fig. $7 E, F$ ), but there were relatively more cells in the $\mathrm{VZ}$ and SVZ (Fig. $7 E, G$ ). Analysis for cell type-specific markers showed that the proportion of transfected Pax6-positive and Tbr2positive cells was increased by Cdc25b overexpression (Fig. $7 \mathrm{H}, \mathrm{I}$ ), whereas Satb2-positive neurons were decreased (Fig. 7J). Thus, Cdc25b overexpression increases precursors at the expense of neurons as has been previously seen in the chick spinal cord (Peco et al., 2012).

We next performed the rescue experiments, electroporating cortices with EGFP, Snail shRNA, and the Cdc25b expression plasmid or an empty vector. Analysis $3 \mathrm{~d}$ later showed that Cdc25b expression did not rescue the Snail knockdownmediated decrease in total number of EGFP-positive cells (Fig. $8 A, B)$, consistent with our finding that this cell number phenotype was dependent upon p53. Moreover, the aberrant localization of EGFP-positive cells caused by Snail knockdown was largely unaffected by Cdc25b expression (Fig. 8C). In contrast, Cdc25b coexpression rescued the Snail knockdown-mediated decrease in proliferating, Ki67-positive cells (Fig. 8D,E) and 
A

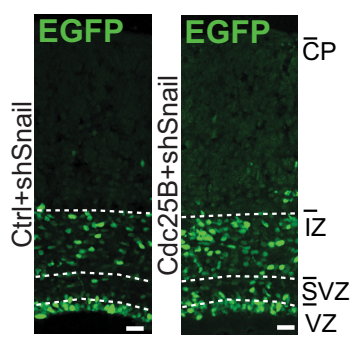

B

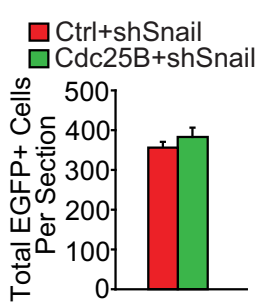

C $\square$ Ctrl+shSnail
$\square$ Cdc25B+shSnail

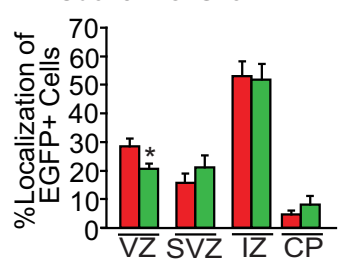

D

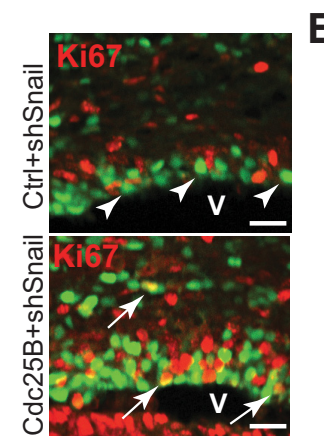

$\mathbf{F}$
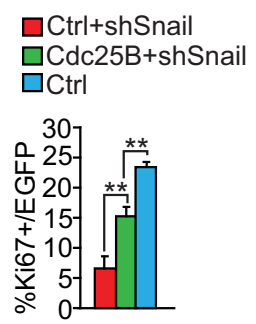
$\square$ Ctrl+shSnail $\square$ Cdc25B+shSnail $\square \mathrm{Ctrl}$

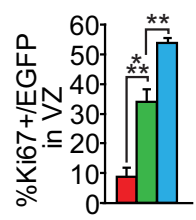

G

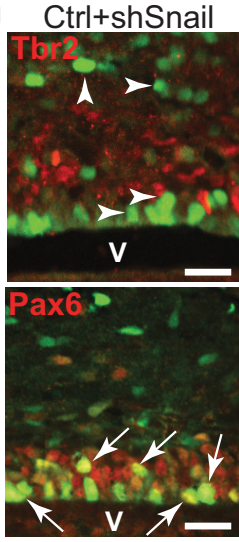

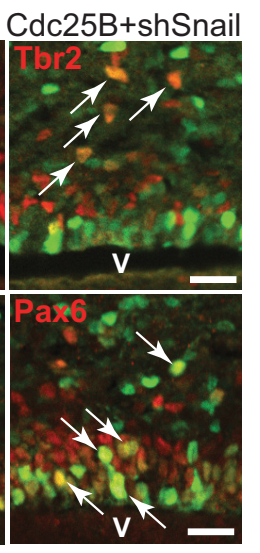

H

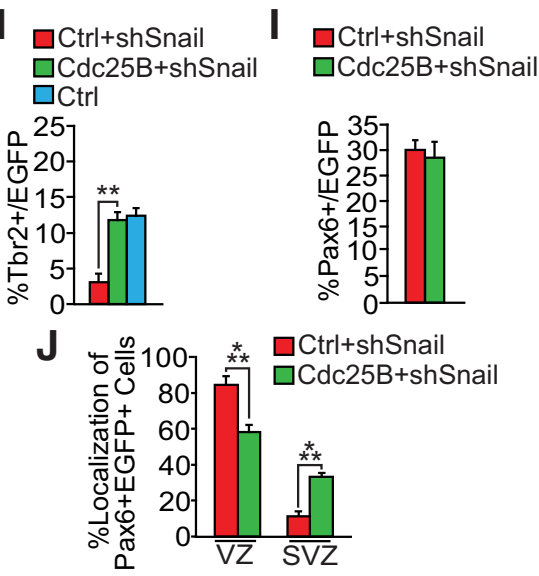

Figure 8. C C 25 b rescues the $p 53$-independent cortical precursor phenotypes caused by Snail knockdown. E13/E14 cortices were electroporated with nuclear EGFP and Snail shRNA plus either a Cdc25b expression plasmid or the empty vector. Cortices were analyzed $3 \mathrm{~d}$ later at E16/E17. A, Coronal cortical sections immunostained for EGFP (green). White lines indicate the cortical regions. Scale bar, $20 \mu \mathrm{m} . \boldsymbol{B}, \boldsymbol{C}$, Quantification of sections as in $\boldsymbol{A}$ for the number $(\boldsymbol{B})$ and relative location $(\boldsymbol{C})$ of EGFP-positive cells. ${ }^{*} p<$ 0.05. $n=3$ embryos each. $\boldsymbol{D}$, Confocal micrographs of the VZ/SVZ immunostained for EGFP (green) and Ki67 (red). Arrows and arrowheads indicate EGFP-positive cells that are positive and negative for Ki67, respectively. V, Ventricle. Scale bar, $20 \mu \mathrm{m} . \boldsymbol{E}, \boldsymbol{F}$, Quantification of sections as in $\boldsymbol{D}$ for the relative proportion of EGFP-positive cells that are also Ki67-positive in the entire cortex $(\boldsymbol{E})$ or in the VZ $(\boldsymbol{F}) .{ }^{*} p<0.01$ (ANOVA with Student-Newman-Keuls post hoc analysis). ${ }^{* *} p<0.001$ (ANOVA with Student-Newman-Keuls post hoc analysis). $n=3$ embryos each. $G$, Confocal micrographs of the VZ/SVZ immunostained for EGFP (green) and Tbr2 (red; top) or Pax6 (red; bottom). Arrows indicate double-labeled cells; arrowheads indicate EGFPpositive cells that are negative for the marker. Scale bar, $20 \mu \mathrm{m}$. $\boldsymbol{H}, \boldsymbol{I}$, Quantification of sections as in $\mathbf{G}$ for EGFP-positive cells that are double-labeled for Tbr2 $(\boldsymbol{H})$ or Pax6 $(\boldsymbol{I}) .{ }^{*} p<0.05$ (ANOVA with Student-Newman-Keuls post hoc analysis). ${ }^{* *} p<0.01$ (ANOVA with Student-Newman-Keuls post hoc analysis). $n=3$ embryos each. $J$, Quantification of sections as in $\mathbf{G}$ for the relative location of Pax6-positive, EGFP-positive cells. ${ }^{* * *} p<0.001 . n=3$ embryos each. Error bars indicate SEM.

increased by approximately fourfold the proportion of proliferating radial precursors in the $\mathrm{VZ}$ (Fig. $8 F$ ). Cdc $25 \mathrm{~b}$ coexpression also completely rescued the Snail shRNA-mediated deficit in Tbr2-positive intermediate progenitors (Fig. 8G,H) as well as the aberrant accumulation of Pax6-positive radial precursor nuclei in the VZ (Fig. 8I,J). Thus, Cdc25b was sufficient to rescue all of the p53-independent precursor phenotypes caused by Snail knockdown but did not rescue the aberrant neuronal localization.

\section{Discussion}

Data presented here indicate that the Snail transcription factor acts via a number of downstream targets to function as a pivotal regulator of mammalian neural precursors. First, our data show that Snail regulates the survival of precursors and newborn neurons by antagonizing a p53-dependent apoptotic pathway. When Snail was knocked down in embryonic cortical radial precursors, this caused increased apoptosis and decreased cortical cell numbers, phenotypes that were rescued by coincident p53 knockdown. Second, our data indicate that Snail acts via the cell cycle phosphatase, Cdc25b, to regulate radial glial precursor proliferation and self-renewal. Specifically, Snail knockdown aberrantly locked radial precursors out of the cell cycle and led to accumulation of their nuclei in the VZ, and these phenotypes were rescued by ectopic expression of Cdc25b. Conversely, Snail overexpression enhanced radial precursor self-renewal. Third, Snail knockdown caused a dramatic decrease in the genesis of intermediate progenitors, and this phenotype was also rescued by Cdc $25 \mathrm{~b}$ coexpression. Thus, Snail controls multiple aspects of neural precursor biology by coincidentally regulating two key downstream pathways.

Experiments presented here establish that Snail regulates survival of developing cortical precursors and newborn neurons by repressing a p53-dependent death pathway. A developmental role for Snail in cell survival is best exemplified by work in C. elegans, where CES-1, the Snail ortholog, participates in a unique asymmetric precursor division, where one daughter cell survives in a CES-1dependent fashion and the other undergoes a $\mathrm{BH} 3$-protein-dependent cell death (Thellmann et al., 2003; Hatzold and Conradt, 2008). Because p53 induces death of mammalian neural precursors via the $\mathrm{BH} 3$ proteins Puma and Noxa (Akhtar et al., 2006; Cancino et al., 2013), then our findings suggest that Snail might also mediate its prosurvival effects in embryonic cortical cells by repressing $\mathrm{BH} 3$ family genes. In this regard, Snail is regulated by numerous growth factors (Nieto, 2002), suggesting that it might provide a key prosurvival intermediary between extrinsic signals and transcription of $\mathrm{BH} 3$ proteins during developmental cell death.

A second striking phenotype observed here was an almost complete loss of radial precursor proliferation after Snail knockdown. This was not the result of cell death because it was still seen when survival was rescued by 553 knockdown. However, radial precursors seemed to be completely locked out of the cell cycle 
because they did not incorporate BrdU or express the cell cycle markers Ki67 or $\mathrm{pH} 3$. We posit that these radial precursors were stalled in $G_{2}$ because most of their nuclei were located proximal to the apical epithelium, which is where they normally reside when in $G_{2}$ and $M$ (Dehay and Kennedy, 2007; Salomoni and Calegari, 2010). Additional support for this idea comes from our experiments showing that $\mathrm{Cdc} 25 \mathrm{~b}$, which plays a key role in triggering the $\mathrm{G}_{2}$ to $\mathrm{M}$ transition (Boutros et al., 2007), is regulated by Snail levels and that it almost completely rescued the proliferation deficit. Intriguingly, when the Snail family member worniu is deleted in Drosophila, the mutant neuroblasts are blocked at the prophase to metaphase transition (Lai et al., 2012); and when all three Drosophila snail family members are deleted, string expression is decreased, and transgenic expression of string (the Drosophila homolog of $\mathrm{Cdc} 25 \mathrm{~b}$ ) can partially rescue the neuroblast phenotypes (Ashraf and Ip, 2001).

One surprising finding reported here is that Snail knockdown caused a dramatic deficit in intermediate progenitors that was not the result of cell death. One explanation for this comes from our finding that coexpression of Cdc25b rescued this phenotype, suggesting that it might be secondary to the radial precursor proliferation deficits. Consistent with this, we show that $\mathrm{Cdc} 25 \mathrm{~b}$ overexpression alone is sufficient to increase intermediate progenitors, and Lange et al. (2009) showed that altering the length of the $G_{1}$ phase in radial precursors enhanced intermediate progenitor genesis. Thus, Snail might normally regulate Cdc25b to control the radial precursor cell cycle and thus the genesis of intermediate progenitors. A second explanation involves inscuteable, which is a direct target of the Snail family in Drosophila neuroblasts (Ashraf and Ip, 2001; Cai et al., 2001) and which regulates radial precursor cell division and genesis of intermediate progenitors in mice (Postiglione et al., 2011). Thus, if inscuteable is a target of Snail in mammals as it is in Drosophila, then aberrant inscuteable regulation might explain, in part, this intermediate progenitor phenotype. However, the $\mathrm{Cdc} 25 \mathrm{~b}$ rescue suggests that, if this is the case, then Inscuteable and Cdc25b must somehow crosstalk downstream of Snail.

One final Snail knockdown phenotype that was not rescued by p53 knockdown or Cdc25b coexpression was mislocalization of newborn neurons in the IZ. What is the cause of this neuronal phenotype? The aberrant neuronal localization suggests a role for Snail in neuronal migration, a role it plays in other cell types (Acloque et al., 2009). One clue to a potential mechanism for this phenotype comes from a recent paper examining two other members of the Snail superfamily, Scratch1 and Scratch2 (Itoh et al., 2013). This study showed that these two proteins are induced at the time when cortical neurons are born and that they function to promote detachment of the apical process and subsequent radial migration of these newborn neurons by regulating expression of the adhesion molecule E-cadherin. Because Snail also represses E-cadherin expression (Batlle et al., 2000) and we show that Snail is expressed in both radial precursors and newborn neurons, then it is tempting to speculate that Snail might collaborate with Scratch1 and Scratch2 to regulate E-cadherin expression and thus neuronal migration, thereby explaining the knockdown phenotype documented here. Such a role in delamination could also explain why Snail overexpression caused Pax6positive radial precursors to move away from the VZ/SVZ and into the intermediate zone. Moreover, if this phenotype was dependent upon E-cadherin, then this would explain why it was not rescued by coincident manipulation of either p53 or Cdc25b. However, although highly suggestive, our current data do not definitively establish a role for Snail in neuronal migration be- cause newborn neurons migrate along the basal processes of radial precursor cells, and the aberrant localization we document could therefore be an indirect effect of the Snail knockdownmediated perturbations in radial precursors. Experiments ablating Snail specifically in newborn neurons and not in precursors will be necessary to directly address this intriguing possibility.

Together, our findings indicate that the transcription factor Snail determines multiple aspects of mammalian neural precursor development and that it does so by coordinately regulating p53 to control their survival, and Cdc25b to regulate their proliferation, self-renewal, and differentiation to intermediate progenitors. Thus, our findings identify a key regulator of mammalian neural stem cell biology and add to an emerging body of evidence indicating that mechanisms that control neural precursor maintenance versus differentiation are conserved between Drosophila and mammals (Schwamborn et al., 2009; Postiglione et al., 2011; Kusek et al., 2012; Vessey et al., 2012).

\section{References}

Acloque H, Adams MS, Fishwick K, Bronner-Fraser M, Nieto MA (2009) Epithelial-mesenchymal transitions: the importance of changing cell state in development and disease. J Clin Invest 119:1438-1449. CrossRef Medline

Akhtar RS, Geng Y, Klocke BJ, Latham CB, Villunger A, Michalak EM, Strasser A, Carroll SL, Roth KA (2006) BH3-only proapoptotic Bcl-2 family members Noxa and Puma mediate neural precursor cell death. J Neurosci 26:7257-7264. CrossRef Medline

Ashraf SI, Ip YT (2001) The Snail protein family regulates neuroblast expression of inscuteable and string, genes involved in asymmetry and cell division in Drosophila. Development 128:4757-4767. Medline

Barnabé-Heider F, Wasylnka JA, Fernandes KJ, Porsche C, Sendtner M, Kaplan DR, Miller FD (2005) Evidence that embryonic neurons regulate the onset of cortical gliogenesis via cardiotrophin-1. Neuron 48:253-265. CrossRef Medline

Bartkowska K, Paquin A, Gauthier AS, Kaplan DR, Miller FD (2007) Trk signaling regulates neural precursor cell proliferation and differentiation during cortical development. Development 134:4369-4380. CrossRef Medline

Batlle E, Sancho E, Francí C, Domínguez D, Monfar M, Baulida J, García De Herreros A (2000) The transcription factor snail is a repressor of E-cadherin gene expression in epithelial tumour cells. Nat Cell Biol 2:8489. CrossRef Medline

Biernaskie J, Paris M, Morozova O, Fagan BM, Marra M, Pevny L, Miller FD (2009) SKPs derive from hair follicle precursors and exhibit properties of adult dermal stem cells. Cell Stem Cell 5:610-623. CrossRef Medline

Boutros R, Lobjois V, Ducommun B (2007) CDC25 phosphatases in cancer cells: key players? Good targets? Nat Rev Cancer 7:495-507. CrossRef Medline

Brummelkamp TR, Bernards R, Agami R (2002) A system for stable expression of short interfering RNAs in mammalian cells. Science 296:550-553. CrossRef Medline

Cai Y, Chia W, Yang X (2001) A family of snail-related zinc finger proteins regulates two distinct and parallel mechanisms that mediate Drosophila neuroblast asymmetric divisions. EMBO J 20:1704-1714. CrossRef Medline

Cancino GI, Yiu AP, Fatt MP, Dugani CB, Flores ER, Frankland PW, Josselyn SA, Miller FD, Kaplan DR (2013) p63 regulates adult neural precursor and newly born neuron survival to control hippocampal-dependent behavior. J Neurosci 33:12569-12585. CrossRef Medline

De Craene B, van Roy F, Berx G (2005) Unraveling signalling cascades for the Snail family of transcription factors. Cell Signal 17:535-547. CrossRef Medline

Dehay C, Kennedy H (2007) Cell-cycle control and cortical development. Nat Rev Neurosci 8:438-450. CrossRef Medline

Dugani CB, Paquin A, Fujitani M, Kaplan DR, Miller FD (2009) p63 antagonizes $\mathrm{p} 53$ to promote the survival of embryonic neural precursor cells. J Neurosci 29:6710-6721. CrossRef Medline

Ellis P, Fagan BM, Magness ST, Hutton S, Taranova O, Hayashi S, McMahon A, Rao M, Pevny L (2004) SOX2, a persistent marker for multipotential 
neural stem cells derived from embryonic stem cells, the embryo or the adult. Dev Neurosci 26:148-165. CrossRef Medline

Gallagher D, Norman AA, Woodard CL, Yang G, Gauthier-Fisher A, Fujitani M, Vessey JP, Cancino GI, Sachewsky N, Woltjen K, Fatt MP, Morshead CM, Kaplan DR, Miller FD (2013) Transient maternal IL-6 mediates long-lasting changes in neural stem cell pools by deregulating an endogenous self-renewal pathway. Cell Stem Cell 13:564-576. CrossRef Medline

Gauthier AS, Furstoss O, Araki T, Chan R, Neel BG, Kaplan DR, Miller FD (2007) Control of CNS cell fate decisions by SHP-2 and its dysregulation in Noonan syndrome. Neuron 54:245-262. CrossRef Medline

Gauthier-Fisher A, Lin DC, Greeve M, Kaplan DR, Rottapel R, Miller FD (2009) Lfc and Tctex-1 regulate the genesis of neurons from cortical precursor cells. Nat Neurosci 12:735-744. CrossRef Medline

Hatzold J, Conradt B (2008) Control of apoptosis by asymmetric cell division. PLoS Biol 6:e84. CrossRef Medline

Hutton SR, Pevny LH (2011) SOX2 expression levels distinguish between neural progenitor populations of the developing dorsal telencephalon. Dev Biol 352:40-47. CrossRef Medline

Itoh Y, Moriyama Y, Hasegawa T, Endo TA, Toyoda T, Gotoh Y (2013) Scratch regulates neuronal migration onset via an epithelialmesenchymal transition-like mechanism. Nat Neurosci 16:416-425. CrossRef Medline

Kusek G, Campbell M, Doyle F, Tenenbaum SA, Kiebler M, Temple S (2012) Asymmetric segregation of the double-stranded RNA binding protein Staufen2 during mammalian neural stem cell divisions promotes lineage progression. Cell Stem Cell 11:505-516. CrossRef Medline

Lai SL, Miller MR, Robinson KJ, Doe CQ (2012) The snail family member Worniu is continuously required in neuroblasts to prevent Elav-induced premature differentiation. Dev Cell 23:849-857. CrossRef Medline

Lange C, Huttner WB, Calegari F (2009) Cdk4/cyclinD1 overexpression in neural stem cells shortens $G_{1}$, delays neurogenesis, and promotes the generation and expansion of basal progenitors. Cell Stem Cell 5:320-331. CrossRef Medline

Nieto MA (2002) The snail superfamily of zinc-finger transcription factors. Nat Rev Mol Cell Biol 3:155-166. CrossRef Medline
Peco E, Escude T, Agius E, Sabado V, Medevielle F, Ducommun B, Pituello F (2012) The CDC25B phosphatase shortens the $G_{2}$ phase of neural progenitors and promotes efficient neuron production. Development 139: 1095-1104. CrossRef Medline

Postiglione MP, Jüschke C, Xie Y, Haas GA, Charalambous C, Knoblich JA (2011) Mouse inscuteable induces apical-basal spindle orientation to facilitate intermediate progenitor generation in the developing neocortex. Neuron 72:269-284. CrossRef Medline

Salomoni P, Calegari F (2010) Cell cycle control of mammalian neural stem cells: putting a speed limit on $\mathrm{G}_{1}$. Trends Cell Biol 20:233-243. CrossRef Medline

Schwamborn JC, Berezikov E, Knoblich JA (2009) The TRIM-NHL protein TRIM32 activates microRNAs and prevents self-renewal in mouse neural progenitors. Cell 136:913-925. CrossRef Medline

Southall TD, Brand AH (2009) Neural stem cell transcriptional networks highlight genes essential for nervous system development. EMBO J 28 : 3799-3807. CrossRef Medline

Thellmann M, Hatzold J, Conradt B (2003) The Snail-like CES-1 protein of C. elegans can block the expression of theBH3-only cell-death activator gene egl- 1 by antagonizing the function of bHLH proteins. Development 130:4057-4071. CrossRef Medline

Tsui D, Vessey JP, Tomita H, Kaplan DR, Miller FD (2013) FoxP2 regulates neurogenesis during embryonic cortical development. J Neurosci 33: 244-258. CrossRef Medline

Vessey JP, Amadei G, Burns SE, Kiebler MA, Kaplan DR, Miller FD (2012) An asymmetrically localized Staufen2-dependent RNA complex regulates maintenance of mammalian neural stem cells. Cell Stem Cell 11:517-528. CrossRef Medline

Woltjen K, Michael IP, Mohseni P, Desai R, Mileikovsky M, Hämäläinen R, Cowling R, Wang W, Liu P, Gertsenstein M, Kaji K, Sung HK, Nagy A (2009) piggyBac transposition reprograms fibroblasts to induced pluripotent stem cells. Nature 458:766-770. CrossRef Medline

Zhou BP, Deng J, Xia W, Xu J, Li YM, Gunduz M, Hung MC (2004) Dual regulation of Snail by GSK-3 [beta]-mediated phosphorylation in control of epithelial-mesenchymal transition. Nat Cell Biol 6:931-940. CrossRef Medline 